OPEN ACCESS

Edited by: Miriam Martini,

University of Turin, Italy

Reviewed by:

Jaroslav Truksa,

Institute of Biotechnology

(ASCR), Czechia

Huakan Zhao,

Chongqing University, China

*Correspondence: Zongfu Pan

panzongfu@hmc.edu.cn Minghua Ge

geminghua@hmc.edu.cn

Specialty section: This article was submitted to

Cancer Metabolism, a section of the journal

Frontiers in Oncology

Received: 09 September 2021 Accepted: 05 November 2021 Published: 02 December 2021

Citation:

Bao L, Xu T, Lu X, Huang P, Pan Z and Ge M (2021) Metabolic Reprogramming of Thyroid Cancer Cells and Crosstalk in Their Microenvironment.

Front. Oncol. 11:773028. doi: 10.3389/fonc.2021.773028

\section{Metabolic Reprogramming of Thyroid Cancer Cells and Crosstalk in Their Microenvironment}

\author{
Lisha Bao ${ }^{1,2,3}$, Tong $\mathrm{Xu}^{4}$, Xixuan $\mathrm{Lu}^{2,3}$, Ping Huang ${ }^{3,4}$, Zongfu Pan ${ }^{3,4^{*}}$ and Minghua $\mathrm{Ge}^{2,3^{*}}$ \\ 1 Second Clinical College, Zhejiang Chinese Medical School, Hangzhou, China, ${ }^{2}$ ENT-Head \& Neck Surgery Center, \\ Department of Head and Neck Surgery, Zhejiang Provincial People's Hospital, Affiliated People's Hospital, Hangzhou Medical \\ College, Hangzhou, China, ${ }^{3}$ Key Laboratory of Endocrine Gland Diseases of Zhejiang Province, Zhejiang Provincial People's \\ Hospital, Hangzhou, China, ${ }^{4}$ Clinical Pharmacy Center, Department of Pharmacy, Zhejiang Provincial People's Hospital, \\ Affiliated People's Hospital, Hangzhou Medical College, Hangzhou, China
}

Metabolism differs significantly between tumor and normal cells. Metabolic reprogramming in cancer cells and metabolic interplay in the tumor microenvironment (TME) are important for tumor formation and progression. Tumor cells show changes in both catabolism and anabolism. Altered aerobic glycolysis, known as the Warburg effect, is a well-recognized characteristic of tumor cell energy metabolism. Compared with normal cells, tumor cells consume more glucose and glutamine. The enhanced anabolism in tumor cells includes de novo lipid synthesis as well as protein and nucleic acid synthesis. Although these forms of energy supply are uneconomical, they are required for the functioning of cancer cells, including those in thyroid cancer (TC). Increasing attention has recently focused on alterations of the TME. Understanding the metabolic changes governing the intricate relationship between TC cells and the TME may provide novel ideas for the treatment of TC.

Keywords: metabolic reprogramming, thyroid cancer, microenvironment, metabolic interplay, Warburg effect

\section{INTRODUCTION}

Thyroid cancer (TC) remains the most frequently diagnosed endocrine malignancy; with a sharp increase in incidence worldwide, this disease is projected to become the fourth leading type of cancer globally (1). Based on its histological features, TC is grouped into four types: papillary thyroid carcinoma (PTC), follicular thyroid carcinoma (FTC), medullary thyroid cancer (MTC), and anaplastic thyroid carcinoma (ATC). Approximately $90 \%$ of all TCs are differentiated, including PTC, which is the most common histological type of differentiated thyroid cancer, followed by FTC (2). Notably, different TC subtypes exhibit distinct tumor aggressiveness and progression and show heterogeneous responses to different treatments (3). Although well-differentiated TCs have good prognoses, approximately $10 \%$ of patients do not respond to radioactive iodine therapy and are more likely to relapse. While the incidence of poorly differentiated TCs such as ATC and MTC is very low, they are characterized by high invasiveness, early metastasis, and poor prognosis $(4,5)$. Conventional therapy consists of surgery, radiotherapy, and endocrine suppression treatment $(6,7)$. However, these treatments have various limitations and side effects $(8,9)$. 
The large differences in metabolism between tumor cells and normal human somatic cells are mainly reflected in catabolic and biosynthesis metabolism (10). The metabolic changes in tumor cells are often considered to be closely related to tumor formation and progression (11). Thus, the unique metabolism of tumor cells is both an opportunity and a challenge. Here, we review the catabolic and anabolic metabolism changes in TC cells. We also describe the mutual relationship between metabolic reprogramming and the tumor microenvironment (TME) in TC, which provides the theoretical basis for new therapeutic targets and prognostic indicators.

\section{METABOLIC CHANGES IN TUMOR CELLS}

Cancer cells always acquire energy and material basis for rapid tumor growth by enhanced anabolism, including rapid aerobic glycolysis, glutaminolysis, de novo lipid synthesis and nucleotide synthesis $(12,13)$. Thyroid cancer cells generate energy primarily by increasing glycolysis and glutaminolysis. In addition, the production of glycolysis can also provide materials for nucleic acid synthesis through pentose phosphate pathway (PPP). Nucleic acid synthesis, protein synthesis, and de novo lipid synthesis are enhanced to support thyroid cancer cell proliferation. During metastasis, tumor cells rely on catabolism to survive from metabolic stress, mainly through aerobic glycolysis, OXPHOS, glutamine metabolism and autophagy to produce ATP (14). Thyroid tumors acquired aggressive phenotype and epithelial-mesenchymal transformation(EMT) via sirtuin 6 (SIRT6)-Autophagy-Warburg Effect Axis (15). AMPK signal is also essential for activating adaptive changes in cell metabolism such as inhibiting anabolism and promoting catabolism, which is the basis for cell survival under metabolic stress. In TC, AMPK activation inhibits TC cell proliferation and promotes cell migration (16). Moreover, carnitine palmitoyltransferase $1 \mathrm{C}$ which is regulated by AMPK, transfers long-chain fatty acids into mitochondria to further oxidation and promotes TC cells survival under metabolic stress conditions (17).

\section{Changes in Catabolism Glucose Metabolism}

Cells produce ATP for energy in two main ways: glycolysis and oxidative phosphorylation (OXPHOS). To satisfy the need of energy for proliferation, thyroid tumor cells increased the level of glycolysis. Although aerobic glycolysis is inefficient compared to OXPHOS, it can provide energy for tumor cell proliferation and invasion and a constant supply of material for biosynthesis (18). The Warburg effect suggests that tumor cells require more glucose than normal cells and derive their energy mainly from glycolysis even when oxygenated adequately (19). However, the energy sources of different tumors also show heterogeneity, and even different areas of the same tumor have different energy sources (20-22). It is noteworthy that glycolysis plays a more important role in sustaining the balance of the PPP in thyroid cells, which is more critical for thyroid hormone synthesis than ATP production even in TC (23) (Figure 1).

Hypoxia-inducible factor (HIF) is a transcription factor that is widespread in mammals and humans under hypoxic conditions. HIF plays roles in glycolysis, promote angiogenesis, cell survival or apoptosis. As the basic regulator of glycolysis, HIF can upregulate the activity of $90 \%$ of glycolytic reactivity enzymes and inhibit the
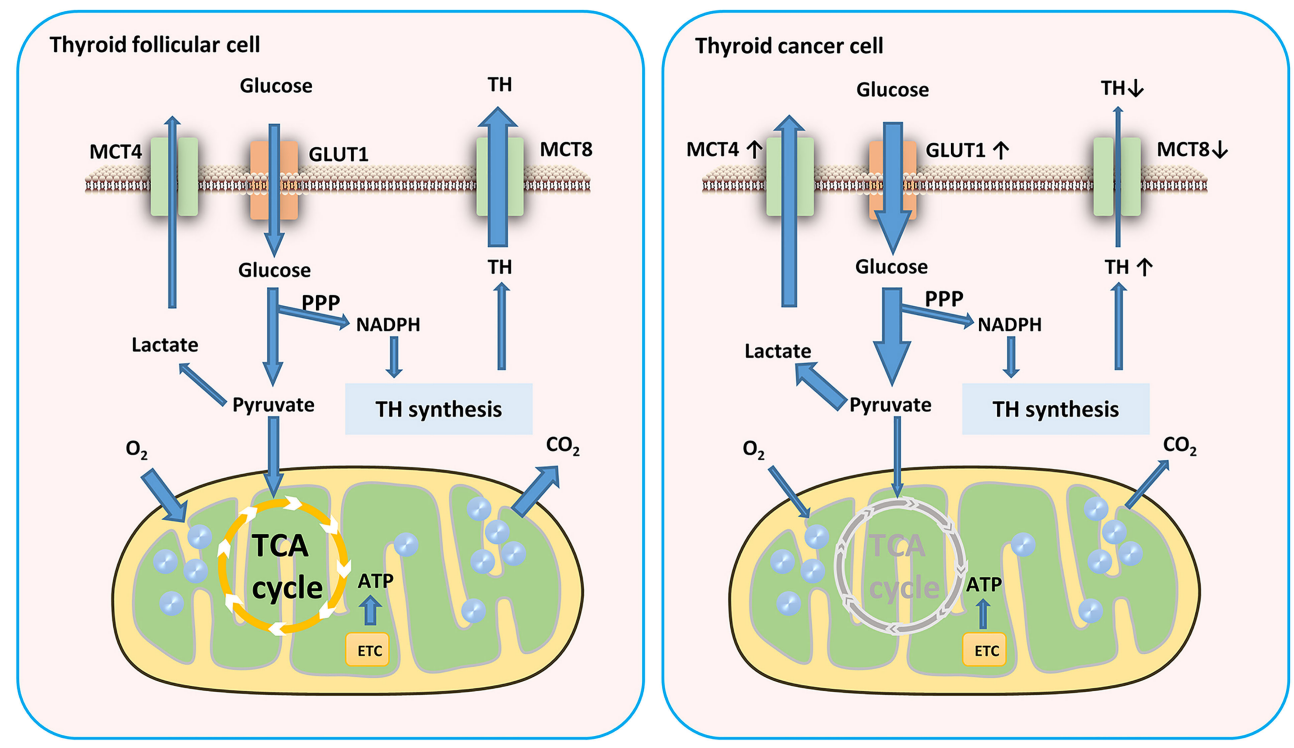

FIGURE 1 | Glucose metabolism in TC cells. TC cells require more glucose than normal cells and derive their energy mainly from glycolysis. This aerobic glycolytic phenotype generates more lactates which transported by MCT4. MCT8 downregulation in TC cells results in TH accumulation in TC tissues. GLUT, glucose transporter; $\mathrm{TH}$, thyroid hormones; ETC, electron transport chain; MCT, monocarboxylate transporter. 
use of pyruvate by mitochondria (24). In TC cells, aerobic glycolysis can be enhanced through the alteration of the HIF1 $\alpha$-MYC-PGC$1 \beta$ axis (25). Zhou et al. showed that hypoxia promoted FTC progression by upregulating HIF1 $\alpha$ and programmed death-ligand 1 (PD-L1) (26). In PTC, SIRT6 promotes the EMT of cancer cells through HIF-1 $\alpha$ (27). Klaus et al. demonstrated the critical role of HIF- $1 \alpha$ in the desmoplastic stroma reaction and metastatic processes in FTC (28). HIF can stimulate the expression of MYC, a transcription factor that is highly expressed in tumors and has a variety of biological functions, including cell metabolism. MYC can promote glycolysis and glucose transporter (GLUT) expression, thus transforming tumor energy metabolism into the Warburg effect (29-31). Myc overexpression can also lead to abnormally increased synthesis of lactate dehydrogenase A (LDHA), which catalyzes pyruvate to lactate. Compared to normal thyroid tissues, LDHA expression is higher in PTC. Hou et al. reported that LDHA not only promoted PTC tumorigenesis but also migration and invasion by regulating autophagy and inducing EMT gene transcription. Moreover, they also found that the metabolic products catalyzed by LDHA increased the acetylation of the related H3K27 and induced EMT (32). LDHA is phosphorylated by HER2 and SRC39, resulting in the increased invasive and metastatic potential of head and neck cancer (33).

GLUT is a transporter that helps cells to take up glucose and is the first rate-limiting step in glucose metabolism. Many studies have demonstrated the upregulation of GLUT subtypes during carcinogenesis (34-36). Samih et al. reported that the phosphoinositide 3-kinase (PI3K)/Akt pathway is the key to GLUT1 transfer from the cytoplasm to the plasma membrane (37). GLUT1 overexpression is also associated with cancer cell aggressiveness and dedifferentiation. Mediated by the transcription factor HIF, GLUT3 is upregulated in response to hypoxia. The overexpression of GLUT1 and GLUT3 is generally recognized as one of the characteristics of tumors (38). Jóźwiak et al. reported that most PTC samples showed higher GLUT1 and GLUT3 expression than the expression in FTC and nonneoplastic thyroid lesions (39). Chai et al. analyzed the expression of GLUT family genes and concluded that the upregulation of the genes encoding GLUT1, GLUT3, GLUT14 was associated with decreased overall survival in patients with PTC (40).The function and tissue distribution of GLUT14 are uncharacterized, although there is some disease association, specifically in inflammatory bowel disease. GLUT14 is a GLUT3 variant that has also been found in the genome as a duplicon of GLUT3. Moreover, the upregulation of GLUT14 was associated with the maintenance of glucose uptake in hypoxia (41). The localization of GLUT1 is heterogeneous among TCs. For example, it exhibits a focal circumferential form in plasma membrane of PTC cells, shows a non-symmetric distribution in the basilar membrane of tumor cells adjacent to the capillary blood supply and stroma, and focal distribution in the center of metastatic tumors or ATC (42). Previous studies indicated that GLUT1 and GLUT3 expression levels may be associated with increased invasion and a worse prognosis of TC. Glucose transported by GLUT involved in glycolysis, the products of which eventually enter the mitochondria to generate ATP for cell energy through OXPHOS. The mitochondrial pyruvate carrier 1 (MPC1) is a critical channel that connects glycolysis to OXPHOS by regulating the transport of pyruvate into the mitochondrial inner membrane. MPC1 deficiency may cause metabolic reprogramming and is associated with a poor prognosis. MPC1 expression is strongly negatively correlated with tumor purity and immune cell infiltration in TC (43).

Many enzymes are involved in the aerobic glycolysis of tumor cells, including pyruvate kinase M2 (PKM2), hexokinase (HK), phosphofructokinase 1 (PKF1). The PI3K/Akt pathway can enhance the Warburg effect of tumors by increasing the activity of these factors (44). HK is the first rate-limiting enzyme in glycolysis and catalyzes the phosphorylation of glucose into glucose 6phosphate. HK2 is also highly expressed in TC $(45,46)$. Huang et al. demonstrated the promotion of thyroid carcinoma cell proliferation and migration through the activation of AKT/mTOR/ HK2-mediated glycolysis (47). Feng et al. reported that PKM2 overexpression in PTC was related to poor clinicopathological features such as advanced tumor stages and lymph node metastasis (48). In their proteomic analysis of five PTC specimens, Aurélie Strickaert et al. investigated the cellular distribution of several upregulated metabolic proteins in the cancerous and stromal cells of these tumors. They discovered the upregulation of many metabolism-related proteins including pyruvate carboxylase (PC) (49). Verhagen et al. compared PK in human thyroid carcinomas, follicular adenomas, and normal thyroid tissue and reported a positive correlation between the specific activities of $\mathrm{PK}$ and tumor proliferation (50). The results of these studies demonstrated that PK overexpression plays an important role in TC.

\section{Amino Acid Metabolism}

Glutamine is a nonessential amino acid in normal cells and can be converted from glucose. However, tumor cells cannot grow in a culture medium without glutamine; thus, glutamine is an essential amino acid in these cells (51). Ample evidence supports the essential role of glutamine in tumors. Tumor cells consume large amounts of glutamine as an alternative energy supply pathway to glycolysis (5254). However, the requirements for glutamine in cancer vary in different tissues and situations (55) (Table 1). Several studies demonstrated the changes in glutamine metabolism of thyroid tumors. Inhibition of glutamine metabolism in TC cells results in insufficient energy supply, which inhibits cell proliferation, migration, and invasion (56). Kim et al. performed tissue microarrays of $557 \mathrm{TC}$ cases and immunohistochemical staining of glutaminolysis-related proteins. They reported that glutaminase 1 (GLS1) and glutamate dehydrogenase (GDH) showed the highest expression in ATC compared to other subtypes. Tumoral amino acid transporter-2 expression was higher in MTC but lower in FTC. In PTC, the expression levels of tumoral GLS1 and GDH were higher in the conventional type than those in the follicular variant, and in the $\mathrm{BRAF}^{\mathrm{V} 600 \mathrm{E}}$ mutation than those in cases without the $\mathrm{BRAF}^{\mathrm{V} 600 \mathrm{E}}$ mutation (57). The expression levels of glutaminolysisrelated proteins including GLS1, GDH, and GLUD were higher in Hürthle cell neoplasm of the thyroid than in those of follicular neoplasm. The expression of SLC1A5 was highest in Hürthle cell adenomas, followed by FC and FA (58). When glutamine enters the 
TABLE 1 | The metabolic differences and similarities in cancers.

\begin{tabular}{|c|c|c|c|}
\hline $\begin{array}{l}\text { Metabolic } \\
\text { pathways }\end{array}$ & Tumor types & Difference & Similarity \\
\hline \multirow[t]{2}{*}{$\begin{array}{l}\text { Glycolysis } \\
\text { metabolism }\end{array}$} & Thyroid cancer & $\begin{array}{l}\text { Produce NAPDH through the PPP pathway for thyroid hormone synthesis, } \\
\text { ATP production (17) }\end{array}$ & $\begin{array}{l}\text { Enhancement of glycolysis and } \\
\text { lactate production }\end{array}$ \\
\hline & Other cancers & Mainly used for ATP production (13) & \\
\hline \multirow{6}{*}{$\begin{array}{l}\text { Energy } \\
\text { source }\end{array}$} & Primary thyroid cancer & Glucose and glutamine metabolism(186) & Increased energy demand \\
\hline & Metastatic thyroid cancer & Unknown & \\
\hline & Primary breast cancer & Glucose and glutamine metabolism (15) & \\
\hline & Metastatic breast cancer & Pyruvate (lung metastases) to sustain the TCA cycle (15) & \\
\hline & & Serine and acetate (brain metastases) to sustain the TCA cycle (16) & \\
\hline & Non-small cell lung cancer & $\begin{array}{l}\text { Carbon source: glucose (areas with low perfusion); glucose and other sources (highly } \\
\text { perfused areas) (14) }\end{array}$ & \\
\hline \multirow[t]{4}{*}{$\begin{array}{l}\text { Lipid } \\
\text { metabolism }\end{array}$} & Thyroid cancer & $\begin{array}{l}\text { Low correlation between MUFAs and MUPCs or monosaturated and polyunsaturated } \\
\text { lipids (85) }\end{array}$ & $\begin{array}{l}\text { Enhancement of de novo lipid } \\
\text { synthesis }\end{array}$ \\
\hline & & ACC2 downregulation (83) & \\
\hline & $\begin{array}{l}\text { Breast, lung, colorectal, } \\
\text { esophageal and gastric } \\
\text { cancer }\end{array}$ & $\begin{array}{l}\text { Highly positive correlation between MUFAs and MUPCs negative correlation between } \\
\text { monosaturated and polyunsaturated lipids (85) }\end{array}$ & \\
\hline & liver, breast and prostate & ACC upregulation (82) & \\
\hline
\end{tabular}

cell, it is hydrolyzed to glutamic acid and ammonia by glutaminase. Glutamate can be converted into $\alpha-K G$ to enter the tricarboxylic acid (TCA) cycle, providing intermediate metabolites and energy for cell metabolism. This is particularly evident in the truncated TCA cycle, which can be used as feedstock for the passive TCA cycle due to the lack of citrate (44). This phenomenon, termed anapleurosis, suggests that the use of glutamine affects glucose absorption. Therefore, reducing the use of glutamine can also reduce that of glucose (59). In general, glucose and glutamine metabolism influence each other. Other changes in protein metabolism are present besides glutamine. Sun et al. analyzed 557 different types of TC and found a higher expression level of serine/glycine metabolism-related proteins in PDC and PTC compared to that in MTC. In PTC, the rate of expression was higher in cases with $\mathrm{BRAF}^{\mathrm{V} 600 \mathrm{E}}$ mutation than in those with a follicular variant (60).

\section{Changes in Biosynthesis Metabolism Enhancement of De Novo Lipid Synthesis}

Compared to normal tissue, tumor cells synthesize lipids more rapidly and from different sources. Accumulating evidence has demonstrated the important role of lipid metabolism reprogramming in tumor cell development and metastasis (6167). Liao et al. reported that lysine methyltransferase 5A (KMT5A), a regulator of lipid metabolism in PTC, was significantly associated with extrathyroidal extension and lymph node metastasis in PTC (68). Instead of nutrient uptake, the raw materials of lipid synthesis in tumor cells mainly come from glucose metabolism. Approximately $93 \%$ of the fatty acids in tumor cells are synthesized de novo $(69,70)$. The enzymes involved in the fatty acid synthesis, such as ATP citrate lyase (ACLY), Acetyl-CoA carboxylase (ACC), and fatty acid synthase (FASN) are changed in tumor cells (71-83). Citrate, the intermediate product of glucose metabolism, forms Ac-CoA under the catalysis of ACLY, and AcCoA forms malonyl CoA (Mal-CoA) under the catalysis of ACC. Ac-CoA and MAL-CoA synthesize palmitic acid catalyzed by
FASN, and palmitic acid forms lipid components required by cells catalyzed by other specific enzymes.

Several studies on thyroid carcinoma also demonstrated lipid metabolism reprogramming. In their transcriptome analysis of lipid metabolism-related genes in PTC, Xu et al. described the use of these genes for PTC classification (84). Recent cases reported by Leng et al. suggested abnormality in the metabolism of fatty acid synthases and lipids. They detected 18 types of FFAs with increased levels in carcinoma tissue compared to the normal tissue of the thyroid (85). Several studies have reported abnormal changes in lipogenic enzymes in TC. FASN is upregulated in various TC subtypes, including PTC, ATC, and FTC (86-88). Under hypoxic conditions, ACC is upregulated in most types of cancer such as liver, breast, and prostate cancer (89) and is downregulated in PTC. The downregulation of ACC2 via $\mathrm{BRAF}^{\mathrm{V600E}}$ plays a critical role in PTC and establishes favorable conditions for TC cell proliferation (90). Of the lipogenic enzymes upregulated in ATC, stearoyl-CoA desaturase-1 (SCD1) that can mediate the desaturation of endogenously synthesized saturated fatty acids into monounsaturated fatty acids (MUFAs) and promote the proliferation of various cancer cell types showed the most significant differential expression when compared with that in normal thyroid tissues (91). A highly positive correlation between MUFAs and monounsaturated phosphatidylcholines (MUPCs) and negative correlations between monosaturated and polyunsaturated lipids have been observed in many types of cancers including breast, lung, colorectal, esophageal, and gastric cancer; thus, similar lipogenic mechanisms may exist to generate the lipids. However, it should be noted that a lower correlation than that mentioned above in TC was observed (92) (Table 1). These findings suggest the presence of different lipid metabolism in TC while it is not clear at this stage. Overall, these cases support the view that TC cells are dependent on de novo lipogenesis for cell viability (Figure 2). 


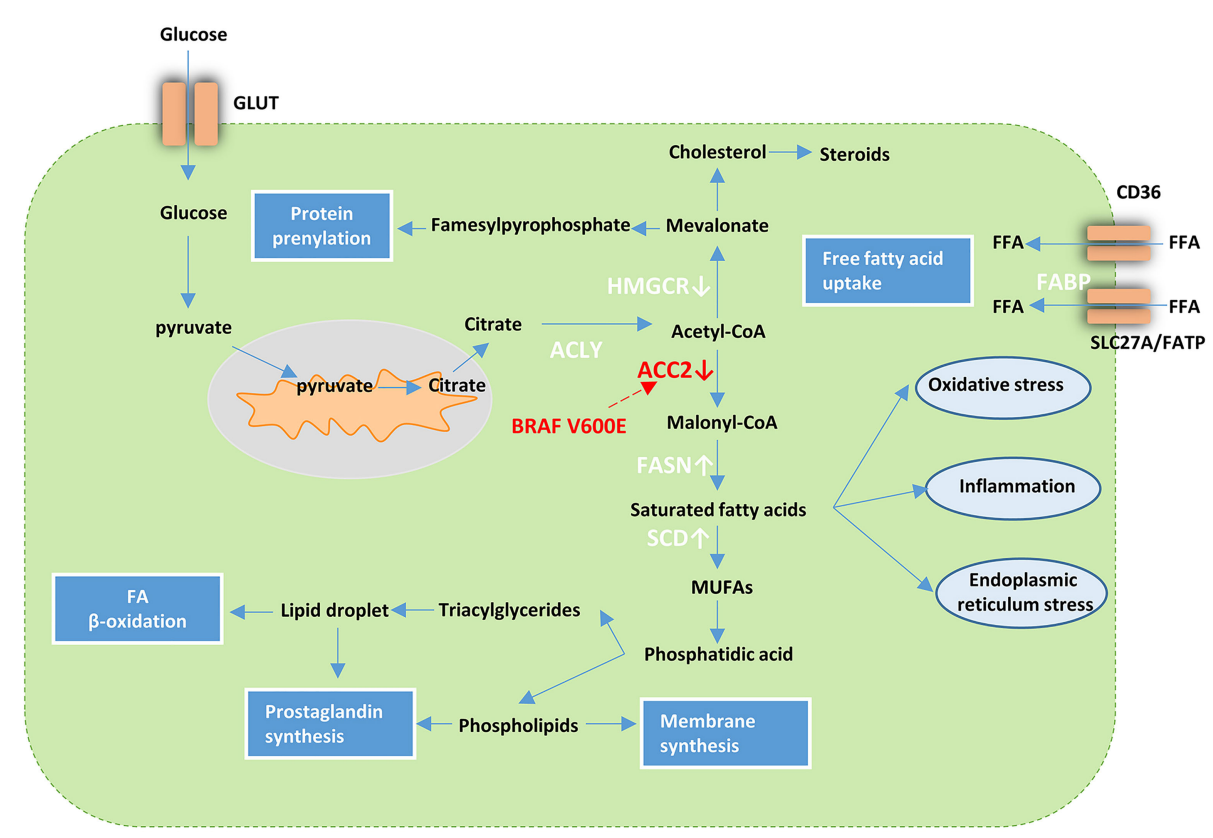

FIGURE 2 | Lipid metabolism in cancer cells. Tumor cells increase FFA uptake via upregulation of fatty acid transport receptors and chaperones such as Solute Carrier SLC27AFATP, CD36, and FABP. In addition, metabolic reprogramming that facilitates glycolysis can activate de novo lipid synthesis. Acetyl-CoA derived from citrate can be further processed into a variety of lipid species with the help of various enzymes. FASN and SCD are upregulated while ACC2 and HMGCR are downregulated in TC. BRAF ${ }^{\mathrm{V} 600 \mathrm{E}}$ influences the lipid metabolism in PTC via downregulation of ACC2. GLUT, glucose transporter; HMGCR, 3-hydroxy-3methylglutaryl-CoA reductase; fatty acid synthase ACLY; ACC2, Acetyl-CoA carboxylase 2; FASN fatty acid synthase; SCD, stearoyl-CoA desaturase-1; MUFAs, monounsaturated fatty acids; FFA, free fatty acid; FABP, fatty acid binding protein; SLC27A, Solute Carrier Family 27; FATP, Fatty Acid Transporter.

\section{Enhancement of Protein Synthesis}

As a crucial component of all cells and tissues of the human body, proteins are the material basis of life. Proteins have many functions in organisms, including catalysis, locomotion, transport, mechanical support, immunity, regulation. Protein synthesis consists of five steps, including amino acid activation, initiation of polypeptide chain synthesis, peptide chain extension, peptide chain termination and release, and postsynthesis processing and modification of the protein. This process expresses the genetic information on messenger RNA (mRNA) transcribed from DNA in the form of proteins. As tumor cells are more metabolically active and divide more frequently than normal cells, they require more proteins.

As mentioned above, the PI3K-Akt-mTOR pathway is activated in various kinds of carcinoma. This pathway is also closely associated with protein synthesis. Tumor cells keep their protein synthesis positive to meet the growth needs through this pathway. In addition, tumor cells have different genetic mutations that activate the synthesis of certain proteins and perform certain functions.

Ribosomes, ribonucleoprotein particles in cells, are mainly composed of numerous distinct proteins and rRNA and are responsible for protein synthesis. In recent decades, many studies have demonstrated the causal associations between inherited mutations affecting ribosome biogenesis and increased cancer risk. Recent studies have shown that dysregulated ribosome biogenesis plays a broader role in the development and progression of most cancers (93-98). Some studies have also assessed the relationship between ribosomes and TC. Saiselet et al. reported that the expression of genes involved in the negative regulation of cell death/apoptosis was also downregulated in five TC cell lines (WRO, FTC133, BCPAP, TPC1, and K1) (99). Jeong et al. discovered the high expression of LXR $\beta$ in TC, which was coordinately associated with ribosome-related genes (100).

\section{Abnormalities in Nucleic Acid Biosynthesis}

Nucleic acid is a biological macromolecule with a nucleotide as its basic unit, which has a complex spatial structure and important biological functions. Nucleic acids can be classified as deoxyribonucleic acid (DNA) and ribonucleic acid (RNA). DNA, which is found in the nucleus and mitochondria, carries genetic information and is passed down through generations through replication. Cell and organismal traits are determined by this genetic information. The two basic pathways of nucleotide synthesis are de novo synthesis and remediation. The de novo synthesis of nucleotides from simple materials such as ribose phosphate, amino acids, one-carbon units, and $\mathrm{CO}_{2}$ is the main synthesis pathway in the human body. The in vivo use of free bases or nucleosides can generate nucleotides through a simple reaction process known as the salvage pathway. Tumor cells use both pathways because they require significant amounts of nucleic acids for rapid growth. As mentioned above, the catabolism of glutamine is particularly active in tumor cells; 
thus, increased amounts of the breakdown products of glutamine are observed when compared with those in normal cells. Ammonia produced by the breakdown of glutamine participates in the ammonia cycle and can be used for the biosynthesis of nucleotides and proteins (101-105).

Tumor cells increase nucleotide synthesis to satisfy their need for growth and proliferation (106). Therefore, the activity of nucleotide synthetase, especially deoxyribonuclease, is higher in tumor cells than that in normal cells (107). The expression of deoxyribonuclease in normal cells fluctuates with changes in the cell cycle. Cancer cells have lost normal regulation and the expression levels are constitutively high, leading to increased DNA synthesis (24). The expression levels of genes involved in DNA replication were upregulated in TC cell lines such as BCPAP and 8505C (99). The occurrence of thyroid tumors is related to abnormal nucleic acid synthesis caused by a variety of gene mutations. The activation of BRAF mutations is a major oncogenic driver of many cancers, especially TC $(108,109)$. BRAF is the predominant mutation (30$40 \%)$ in PTC and is considered an initiating event in papillary thyroid carcinogenesis. Another human gene involved in thyroid carcinogenesis is TERT, which contributes to the distant metastasis (110-112).

\section{TC CELL METABOLISM AND THE TME}

\section{Tumor Cell Metabolism Shapes the Inflammatory TME}

The two major characteristics of the TME are hypoxia and acidification, which are closely related. Tumor cells increase glycolysis to adapt to the hypoxic microenvironment. The lactate produced by glycolysis, in turn, acidifies the TME. In addition, the incomplete vasculature of tumor tissue prevents the timely elimination of metabolites, which is also related to the acidification of the TME. Active metabolism in TME cells can also lead to increased toxic concentrations of certain metabolites, such as increased levels of adenosine, kynurenine, ornithine, reactive oxygen species, and potassium. These metabolites have profound effects on suppressing the tumor immune response. During tumor development, the TME changes continuously with tumor growth and develop its cellular contents by releasing various recruiting factors, leading to the accumulation of specific types of immune cells in the TME, also affects the functions of these immune cells and the complex relationship between these cells and tumor cells. Thus, tumors are no longer simply a problem of cancer cells. Co-evolution occurs between tumor cells and the surrounding stromal cells, forming an inseparable community. Under the influence of tumor cells, tumor stromal fibroblasts, macrophages, and neutrophils become tumor-associated fibroblasts (CAFs), tumor-associated macrophages (TAMs), and tumor-associated neutropenia.

\section{Metabolic Crosstalk in the TC Microenvironment Nutrient Competition}

The high metabolic activity of cancer cells and the disordered vasculature in the TME can contribute to a microenvironment featuring nutrient depletion and hypoxia, which established a metabolic competition between cancer cells and infiltrating immune cells. This series of changes and metabolic reprogramming plays a significant role in promoting tumor growth and immune escape. Chen et al. compared human normal thyroid and PTC samples and identified metabolites in carbohydrate metabolism, including glucose, that consistently decreased in PTC (113). The lack of glucose impaired the function of immune cells such as TAMs and T cells by regulating mTOR and GAPDH. Glycolysis promotes effector T cell (Teff cell) function by sustaining the production of IFN $\gamma$. Decreased mTOR activity diminishes IFN $\gamma$ at the transcriptional level in $\mathrm{CD}^{+} \mathrm{T}$ cells and, thus, impairs $\mathrm{T}$ cell function $(114,115)$. Besides glucose, amino acids also play a role in driving and fueling $\mathrm{T}$ cell function and differentiation. The neighboring immune cells in solid tumors are outcompeted due to arginine uptake and catabolism which primarily shifts toward cancer cells (116). Leone et al. reported that tumor cells exposed to glutamine antagonist showed decreased viability, proliferation, and cell cycle progression while Teff cells produce a long-lived, highly activated phenotype by markedly upregulating oxidative metabolism (117).

\section{Secreted Metabolites}

The accumulation of metabolites such as lactate, kynurenine, and other metabolic by-products of cancer metabolism can be detrimental to immune cells, leading to tumor immunosuppression. Indoleamine 2, 3-dioxygenase (IDO), a rate-limiting enzyme in tryptophan oxidation, promotes tryptophan uptake from the TME and generates kynurenine, which inhibits tryptophan import. Therefore, the amino acids of $\mathrm{T}$ cells are depleted and result in immunosuppression and induced $\mathrm{T}$ cell apoptosis. IDO-expressing tumor cells are not rejected by specific $\mathrm{T}$ cells through the secretion of kynurenines, which can suppress cytotoxic effector functions via the downregulation of TCR CD3 $\zeta$-chain and induced $\mathrm{FOXP}^{+}$ regulatory $\mathrm{T}$ cell (Treg) differentiation. IDO upregulation impaired the function of NK cell function and boost the high infiltration of FOXP3 $^{+}$Tregs in thyroid carcinoma $(118,119)$. In addition, Foxp $3^{+}$ Tregs in lymphocytes facilitate thyroid tumor growth and invasion (120). A large amount of lactate can also cause acidosis in the microenvironment and weaken immune cell function (121). Arts et al. showed that TC-derived lactate-mediated TC-induced TAM reprogramming and inflammation through Akt/mTOR-dependent glycolysis, an increase in inflammation characteristics, and changes in cell metabolism (122). The accumulation of lactate is also detrimental to the function and antitumor response of $\mathrm{T}$ and $\mathrm{NK}$ cells by inhibiting proliferation and cytokine production (123). These studies suggested that patients with cancer should be cautious when using lactate preparations, as lactate may promote tumor growth.

Tumor cells also secrete vascular endothelial growth factor (VEGF) into the TME, resulting in the upregulation of 6phosphofructo-2-kinase/fructose-2, 6-biphosphatase 3 (PFKFB3) in endothelial cells, which activates PFK-1 to promote the glycolytic phenotype as well as proliferation (124). Colegio et al. demonstrated that lactate produced by tumor cells promotes M2 macrophage polarization by a HIF1a-dependent mechanism. In turn, VEGF and Arginase- 1 secreted by 
M2-polarized macrophages signal back to tumor cells and promote tumor growth (125).

\section{Metabolic Coupling}

In TME, the energy metabolism of CAFs shifts to aerobic glycolysis under the influence of cancer cells. The lactate, ketone body, or pyruvate released by these CAFs can be used as an energy source by epithelial cancer cells to enter the TCA cycle and produce ATP through OXPHOS. This phenomenon is called the reverse Warburg effect. Lactate produced by CAFs is exported via the monocarboxylate transporter (MCT)-4 into the TME and taken up by tumor cells via the MCT-1 transporter. Such metabolic coupling has been reported in several tumor types including head and neck cancer (126). In addition, the metabolic coupling between PTC cells and adjacent fibroblasts can result in aggressive behavior owing to the large-scale production lactate, which is transported outside the cell by MCT4 (127). CAFs also increased the anabolic metabolism of glutamine which can be consumed by cancer cells to sustain nucleotide generation and OXPHOS. In contrast, glutamate secreted by cancer cells promoted the production of glutathione (GSH), thereby maintaining redox balance and ECM remodeling in CAFs (128). The results of Mestre-Farrera et al. indicated that glutamine deprivation promoted CAFs migration and invasion, which, in turn, promotes tumor epithelial cells to move to nutrientrich areas (129). CAFs release paracrine signals to induce metabolic reprogramming and epigenetic changes, causing changes similar to KRAS-driven oncogenic transformations (130). Tumors cells release factors such as PDGF and TGF- $\beta$, resulting in metabolic reprogramming of CAFs toward aerobic glycolysis $(131,132)$. Fozzatti et al. described the significant increase of GLUT-1 in human fibroblasts in vitro when cultured in ATC cells-derived conditioned media. Strikingly, conditioned media obtained from these activated fibroblasts promoted cell proliferation and invasion of follicular TC cell line (133). Rabold et al. performed transcriptome, metabolome, and lipidome analyses on TCinduced macrophages in a human coculture model. The lipidome analysis showed increased total lipid and intracellular lipid content of tumor-induced macrophages, especially phosphoglycerides and sphingolipids. Remarkably, this metabolic shift in lipid synthesis contributes to their protumoral functional characteristics: a block of key enzymes of lipid biosynthesis in tumor-induced macrophages reversed elevated inflammatory cytokines and the ability to produce ROS, two well-known pro-tumoral factors in the TME (134).

These studies show the complicated and dynamic interaction that exists between thyroid tumors and immune cells in TME, which results in the promotion of thyroid tumorigenesis (Figure 3).

\section{PROGNOSTIC BIOMARKERS AND TREATMENT}

\section{Prognostic Indicators}

In conclusion, the expression of metabolism-related molecules revealed the differences in invasiveness and prognosis between different TC subtypes (Figure 4). Numerous studies have demonstrated the relationship between the prognosis of thyroid carcinoma and glycolysis-related proteins such as GLUT, LDHA, MCT1 (32, 135, 136). Some studies have indicated that GLUT contributed to the increased glucose uptake observed during carcinogenesis $(135,137)$. The differentiated extent of thyroid cancer is negatively correlated with the expression of GLUTs. Poorly differentiated types such as ATC have high expression levels of GLUT (mainly GLUT-1); in contrast, well-differentiated tumors such as FTC and PTC usually have low GLUT-1 expression levels (45, 137-140). Glutamine, serine, glycine, and other amino acid metabolism-related proteins can also be used as prognostic indicators for thyroid tumors. Stromal GDH positivity was an independent factor associated with poor prognosis. In follicular variant PTC, stromal serine hydromethyl transferase 1 expression was associated with shorter disease-free survival. The serine/glycine metabolism-related molecules phosphoglycerate dehydrogenase, glycine decarboxylase, and phosphoserine phosphatase positivity were associated with shorter overall survival (57, 58, 60, 141). IDO, which was associated with the aggressive features of papillary thyroid microcarcinoma, may disrupt antitumor immunity and contribute to tumor progression by increased infiltration of $\mathrm{FOXP}^{+}$ Treg cells (142).

\section{Metabolism Targeted Therapy}

At present, cancer therapeutic regimens face the problem of drug resistance which may associate with metabolic reprogramming in tumor. Therefore, combination therapies that target various tumor cell properties showed great potential value. Metabolic inhibitors in combination with targeted therapy or chemotherapy hold promise for increasing anticancer drug sensitivity.

\section{Glucose Metabolism as a Therapeutic Target}

The energy supply of tumor cells differs from that of normal cells. This unique energy supply pathway is mainly due to increased glycolytic enzyme expression and activity levels. Theoretically, inhibiting specific glycolytic metabolic enzymes with high expression levels can cut off the energy supply of tumor cells, while normal tissues are not affected. When the glycolytic pathway is inhibited, normal tissue cells can utilize fatty acid and amino acid production through alternative pathways. Some glycolytic enzymes, such as HK-II LDHA, and PKM2, are highly expressed in malignant tumors. These highly expressed glycolytic enzymes can be used as targets for tumor treatment (143). Due to tumor cell heterogeneity and TME variability, the expression and activity of glycolytic enzymes may change. Consequently, the therapeutic effect of a single glycolytic enzyme target may not be as good as that for the combination of multiple glycolytic enzyme targets. Combinations involving the inhibition of glycolysis and OXPHOS, or glycolysis and glutaminolysis have been proven in multiple preclinical cancer models to effectively suppress tumor growth (144-148). Glyoxalase I (GLO I) is a rate-limiting enzyme that is involved in the detoxification of cytotoxic methylglyoxal formed in glycolysis. The combination of GLO I inhibitor with shikonin, a PKM2 specific inhibitor, could suppress the cellular proliferation and induction of apoptosis (149).

Various HK2 inhibitors have been identified, including 2deoxyglucose(2-DG), 3-bromopyruvate (3-BP), and lonidamine (LND). In thyroid tumors, glycolytic inhibitors also show unique 


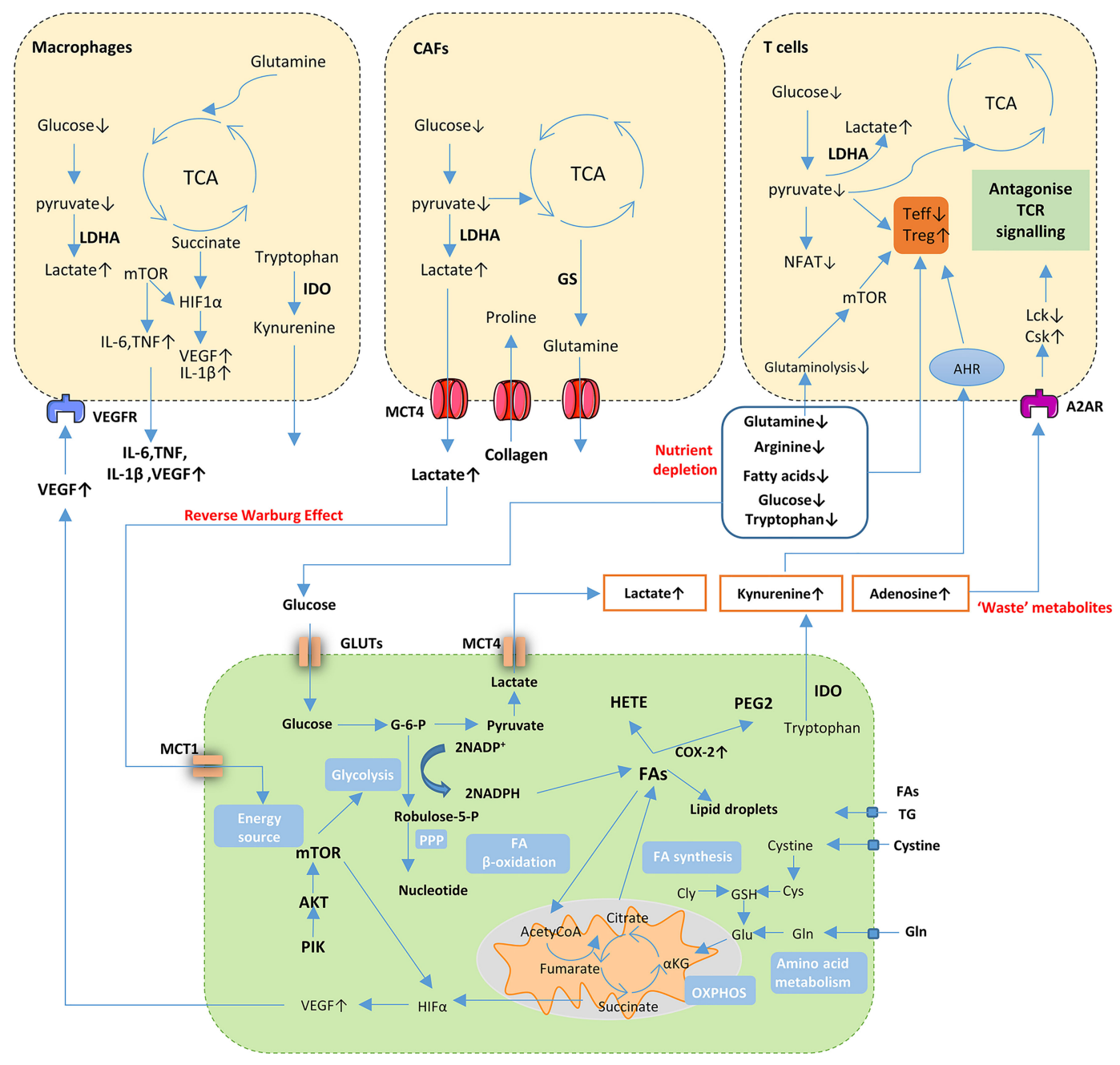

FIGURE 3 | Cancer cell metabolism and crosstalk in the TME. Cancer cells undergo metabolic changes including activation of aerobic glycolytic, enhanced FA synthesis and increased uptake of glutamine supply for bioenergetics through tricarboxylic acid (TCA) cycle and support biosynthesis of proteins. Nutrient depletion, accumulation of 'waste' metabolites and aberrant signaling molecules in TME influence the function and proliferation of both cancer cells and immune or stromal cells. Gln, glutamine; Glu, Glutamate; Cys, cysteine; GSH, glutathione; Cly, glycine; TG, triglyceride; FA, fatty acids; PPP, pentose phosphate pathway; NADH, nicotinamide adenine dinucleotide; NADPH, nicotinamide adenine dinucleotide phosphate; HETE, thromboxane hydroxiepoxyeicosate-traenoic acid; PEG2, prostaglandin E2; COX-2, cyclooxygenases-2; G-6-P, glucose-6-phosphate; IDO, Indoleamine 2, 3-dioxygenase; MCT, monocarboxylate transporter; GLUT, glucose transporter; VEGF, vascular endothelial growth factor; LDHA, lactate dehydrogenase A; GS, glutamine synthetase; NFTA, nuclear factor of activated T cells; AHR, aryl hydrocarbon receptor; A2AR, Adenosine 2A receptor; Csk, C-terminal Src kinase; Lck, lymphocyte-specific protein tyrosine kinase; Teff, effector T cells; Treg, regulatory $T$ cells.

therapeutic effects. Glycolytic inhibition with 3-BP suppress tumor growth and extends survival in a murine model of ATC when combined with the ketogenic diet (150). It has been previously shown that glycolytic inhibitors 2DG significantly enhanced the antitumor effects of other medical treatments and radiotherapy (151-154). Phase I/II clinical trials have been performed for 2-DG as a single-agent therapy in solid tumors and hormone-refractory prostate cancer. However, further research was halted owing to the significant toxicities and limited efficacy (NCT00633087) (155). LND also reached phase II and III clinical trials for the treatment of several tumor types but showed only modest clinical activity and a lack of specificity. Moreover, due to concerns regarding liver enzyme abnormalities, further research was halted $(156,157)$. Targeted therapy is a common treatment for thyroid tumors. When blocking platelet-derived growth factor receptor by imatinib, the pro-oncogene $\mathrm{BRAF}^{\mathrm{V} 600 \mathrm{E}}$ promotes thyroid tumor cell glycolysis via the upregulation of HK2 expression, resulting in drug resistance. However, glucose uptake and metabolism in thyroid tumor cells were downregulated when $\mathrm{BRAF}^{\mathrm{V} 600 \mathrm{E}}$ was blocked by vemurafenib. In terms of tumor growth, combination therapy of imatinib and vemurafenib was much more effective than single therapy and led to a near abolition of the tumors (158). The combination of imatinib 

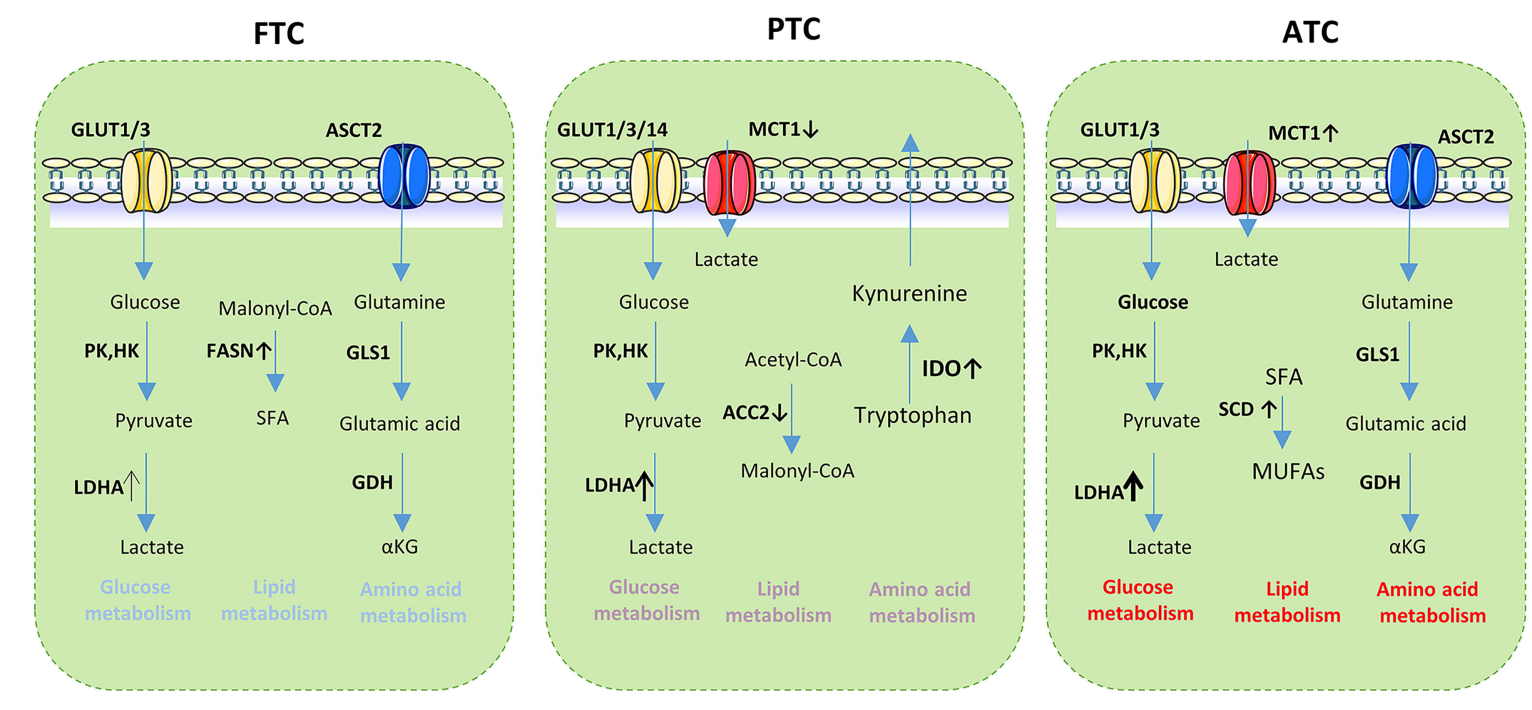

\section{Metabolism-related Molecules: \\ GLUT1, GLS1,GDH}

\section{Survival risk}

FIGURE 4 | Metabolism-related molecules is related to the aggressiveness of thyroid cancer and survival risk. GLUT, glucose transporter; LDHA, lactate dehydrogenase A; PK, Pyruvate kinase; HK, hexokinase; SFA, saturated fatty acids; ASCT, amino acid transporter; FASN, fatty acid synthase; GLS1, glutaminase 1; GDH, glutamate dehydrogenase; ACC2, Acetyl-CoA carboxylase 2; IDO,Indoleamine 2, 3-dioxygenase; SCD1, stearoyl-CoA desaturase-1; MUFAs, monounsaturated fatty acids.

and HK2 inhibitors may solve the problem of drug resistance and also provide better efficacy in TC.

$\mathrm{LDH}$ is a critical metabolic enzyme that is considered a hallmark of aggressive malignancies. Radiotherapy is a common therapy in thyroid cancer, indicating the combination therapy of LDHA inhibitor and radiotherapy may be efficient in thyroid cancer. Chen et al. find LDHA suppression monotherapy decreased cellular proliferation and stunted tumor growth temporarily in ATC but cannot achieve tumor cure, due to the maintenance of residual viable cells. Only the combination therapy of chronic LDHA suppression and radiation can achieve a functional cure (159). Various LDHA inhibitors have been developed, such as dichloroacetate (DCA), gossypol, oxamate and FX-11 (160-162). The lactate transporter MCT links intracellular lactate with the TME and plays an indispensable role in tumor lactate metabolism. AZD3965 is an inhibitor of the MCT-1/MTC-2 lactate transporter and reached phase I clinical trials for both solid tumors and large Bcell lymphoma (NCT01791595). However, MCT inhibition also impairs T cell proliferation (Table 2).

\section{Amino Acid Metabolism as a Therapeutic Target}

Amino acids are an essential component of tumor cells and are closely related to tumor development. Thus, amino acid metabolism may provide a new therapeutic perspective.
Lasparaginase is approved by the Food and Drug Administration for the frontline treatment of acute lymphoblastic leukemia (163). Other treatments for amino acid deprivation have also shown encouraging results in clinical trials in several solid malignancies (164-167). The mitochondrial enzyme GLS plays a crucial role in glutaminolysis. Among the GLS inhibitors, CB-839 is more potent, selective and shows greater bioavailability. In phase I clinical trials, CB-839 showed preliminary signs of clinical activity with an acceptable safety profile in multiple tumor types including triplenegative breast cancer, non-small cell lung adenocarcinoma, renal cell carcinoma, mesothelioma, and tumors with mutations in enzymes in the TCA cycle (NCT02071862) (168).

Since tumor cells require glutamine, one possible strategy is to treat tumors by preventing or interfering with glutamine metabolism by tumor cells. The blockade of glutamine in tumorbearing mice inhibited cancer cell oxidation and glycolytic metabolism, resulting in hypoxia, acidosis, and reduced nutrient consumption (117). However, some studies showed that increasing the intake of glutamine in tumor-bearing rats did not elevate the growth rate of tumors; moreover, clinical work has also shown that glutamine supplementation in patients with tumors improved chemotherapy efficacy and reduced the adverse reactions (169173). IDO, the ratelimiting enzyme in tryptophan catabolism, is highly expressed in TC cells and suppresses the function of NK cells. 
TABLE 2 | Metabolism-targeting cancer therapies.

\begin{tabular}{|c|c|c|c|c|c|c|c|}
\hline \multicolumn{2}{|c|}{$\begin{array}{l}\text { Target pathway and } \\
\text { protein }\end{array}$} & \multirow{2}{*}{$\begin{array}{l}\text { Agent } \\
\text { 2-DG }\end{array}$} & \multirow{2}{*}{$\begin{array}{c}\begin{array}{c}\text { Study } \\
\text { phase }\end{array} \\
\text { Phase II }\end{array}$} & \multirow{2}{*}{\begin{tabular}{l}
\multicolumn{1}{c}{ Effects } \\
$\begin{array}{l}\text { Limited efficacy on tumor growth and significant } \\
\text { toxicities }\end{array}$
\end{tabular}} & \multirow{2}{*}{$\begin{array}{l}\text { Interventions } \\
\text { Single agent }\end{array}$} & \multirow{2}{*}{$\begin{array}{c}\text { References } \\
\text { NCT00633087 }\end{array}$} & \multirow{2}{*}{$\begin{array}{c}\text { Status } \\
\text { Terminated }\end{array}$} \\
\hline $\begin{array}{l}\text { Glucose } \\
\text { metabolism }\end{array}$ & HK2 & & & & & & \\
\hline & & LND & Phase III & $\begin{array}{l}\text { Limited efficacy and produced more myalgias and } \\
\text { fatigue }\end{array}$ & Combined with epirubicin & (150) & \\
\hline & & 3-BP & Preclinical & $\begin{array}{l}\text { Suppresses tumor growth and improves survival in } \\
\text { vivo }\end{array}$ & $\begin{array}{l}\text { combined with the ketogenic } \\
\text { diet }\end{array}$ & (143) & \\
\hline & & Gossypol & Phase I/II & Safe and well tolerated but shown limited activity. & Single agent & (1153) & \\
\hline & & Oxamate & Preclinical & $\begin{array}{l}\text { Inhibits the viability of cancer cells in a dose- and } \\
\text { time-dependent manner }\end{array}$ & & $(155)$ & \\
\hline & & $\mathrm{FX}-11$ & Preclinical & Block aerobic glycolysis and growth cancer in vitro & Single agent & (154) & \\
\hline $\begin{array}{l}\text { Amino acid } \\
\text { metabolism }\end{array}$ & GL1 & CB-839 & Phase II & & Combined with Paclitaxel & NCT03057600 & Completed \\
\hline \multirow[t]{4}{*}{$\begin{array}{l}\text { Lipid } \\
\text { metabolism }\end{array}$} & ACC & ND-654 & Preclinical & $\begin{array}{l}\text { Inhibits the tumor development in vivo, improve } \\
\text { survival rate }\end{array}$ & $\begin{array}{l}\text { Single agent; combined with } \\
\text { the sorafenib }\end{array}$ & (68) & \\
\hline & SCD & SSI-4 & Preclinical & $\begin{array}{l}\text { Regulate tumor-initiating cells and sorafenib } \\
\text { resistance }\end{array}$ & Combined with sorafenib & $(182)$ & \\
\hline & & $\begin{array}{l}\text { Betulinic } \\
\text { acid }\end{array}$ & Preclinical & Induces rapid cell death & Single agent & $(184)$ & \\
\hline & & MF-438 & Preclinical & Achieve better control & Combined with cisplatin & (183) & \\
\hline
\end{tabular}

IDO inhibitors such as epacadostat have reached phase III trials and show promising efficacy in combination therapies by linking metabolism and immunomodulation. Therefore, IDO inhibitors are likely to be useful for the treatment of thyroid tumors (174).

\section{Lipid Metabolism as a Therapeutic Target}

ACC is a rate-limiting enzyme for de novo lipid synthesis and inhibition of fatty acid oxidation. Rescue of ACC2 may be a new molecular strategy to overcome the resistance of refractory PTC to $\mathrm{BRAF}^{\mathrm{V} 600 \mathrm{E}}$ inhibitors (90). SCD is an aliphatic acyl desaturase that catalyzes the transformation of saturated fatty acids into MUFAs by inserting cis-double bonds at the $\Delta 9$ position of the carbon chain (175). MUFAs play a role in cell growth, survival, differentiation, metabolic regulation, and signal transduction. SCD has been observed in a wide range of cancer cells (176-179) and this increase is closely associated with cancer aggressiveness and poor prognosis (180-183). Previous research established SCD reduces cell proliferation and invasion by blocking cell migration and membrane fluidity (184-187). In ATC, therapeutic and genetic- targeted inhibition of SCD enzyme activity promoted a significant reduction in cell proliferation and induced cell death, while normal thyroid cells were unaffected (91). SCD inhibitors such as SSI-4, betulinic acid, and MF-438 that proved effective in antitumor effect (188-190) may show a promising efficiency in the treatment of thyroid cancer.

\section{CONCLUSION AND PERSPECTIVE}

The crucial of metabolic reprogramming in tumor development and metastasis is increasingly recognized (Table 3). The complicated relationship between tumor cell metabolism and the TME is also important. Tumor cell metabolism can cause acidification of the TME and can also recruit immune cells to change immune cell metabolism in the TME. However, the immune microenvironment can also act on tumor cells to promote the immune escape of tumor cells.

Although there has been some progress in the study of metabolic reprogramming of $\mathrm{TC}$ in recent years, there remain

TABLE 3 | Metabolic reprogramming between proliferation and metastasis in thyroid cancer.

\begin{tabular}{|c|c|c|c|c|}
\hline Metabolism pathways & & Function & Reference & Evidence \\
\hline \multirow[t]{2}{*}{ Glucose metabolism } & LDHA & Migration, invasion, tumor growth & (26) & In vivo and in vitro \\
\hline & HK2 & Proliferation, migration & (41) & In vitro \\
\hline Amino acid metabolism & IDO & Tumor growth and invasion & $(135)$ & Clinical relevance \\
\hline \multirow[t]{2}{*}{ Lipid metabolism } & SREBP1, SCD, FASN and ACC & Extrathyroidal extension, lymph node metastasis, migration and invasion & $(61)$ & $\begin{array}{l}\text { Clinical relevance, } \\
\text { in vitro }\end{array}$ \\
\hline & SCD1 & Proliferation and viability & (84) & In vitro \\
\hline
\end{tabular}


many gaps to fill. Some outstanding questions still need to be addressed for the development of specific metabolic targeted therapy. More studies are needed to determine how thyroid tumor cell metabolism interacts with immune cells in the microenvironment, which metabolic targets can be blocked specifically for TC treatment, the possible side effects of metabolism inhibitors, and the solutions to these challenges.

\section{AUTHOR CONTRIBUTIONS}

Conceived the work: LB and ZP. Wrote the manuscript: LB. Generated data for figures: TX and XL. Revised the manuscript:

\section{REFERENCES}

1. Kim J, Gosnell JE, Roman SA. Geographic Influences in the Global Rise of Thyroid Cancer. Nat Rev Endocrinol (2020) 16:17-29. doi: 10.1038/s41574019-0263-x

2. Kitahara CM, Sosa JA. The Changing Incidence of Thyroid Cancer. Nat Rev Endocrinol (2016) 12:646-53. doi: 10.1038/nrendo.2016.110

3. Cabanillas ME, McFadden DG, Durante C. Thyroid Cancer. Lancet (2016) 388:2783-95. doi: 10.1016/s0140-6736(16)30172-6

4. Nikiforova MN, Nikiforov YE. Molecular Genetics of Thyroid Cancer: Implications for Diagnosis, Treatment and Prognosis. Expert Rev Mol Diagn (2008) 8:83-95. doi: 10.1586/14737159.8.1.83

5. Molinaro E, Romei C, Biagini A, Sabini E, Agate L, Mazzeo S, et al. Anaplastic Thyroid Carcinoma: From Clinicopathology to Genetics and Advanced Therapies. Nat Rev Endocrinol (2017) 13:644-60. doi: 10.1038/ nrendo. 2017.76

6. Filetti S, Durante C, Hartl D, Leboulleux S, Locati LD, Newbold K, et al. Thyroid Cancer: ESMO Clinical Practice Guidelines for Diagnosis, Treatment and Follow-Up†. Ann Oncol (2019) 30:1856-83. doi: 10.1093/ annonc/mdz400

7. Grani G, Lamartina L, Durante C, Filetti S, Cooper DS. Follicular Thyroid Cancer and Hürthle Cell Carcinoma: Challenges in Diagnosis, Treatment, and Clinical Management. Lancet Diabetes Endocrinol (2018) 6:500-14. doi: 10.1016/s2213-8587(17)30325-x

8. Tuttle RM. Controversial Issues in Thyroid Cancer Management. J Nucl Med (2018) 59:1187-94. doi: 10.2967/jnumed.117.192559

9. Raue F, Frank-Raue K. Thyroid Cancer: Risk-Stratified Management and Individualized Therapy. Clin Cancer Res (2016) 22:5012-21. doi: 10.1158/ 1078-0432.Ccr-16-0484

10. Hay N. Reprogramming Glucose Metabolism in Cancer: Can it be Exploited for Cancer Therapy? Nat Rev Cancer (2016) 16:635-49. doi: 10.1038/ nrc. 2016.77

11. Faubert B, Solmonson A, DeBerardinis RJ. Metabolic Reprogramming and Cancer Progression. Science (2020) 368:eaaw5473. doi: 10.1126/ science.aaw5473

12. Cha YH, Yook JI, Kim HS, Kim NH. Catabolic Metabolism During Cancer EMT. Arch Pharm Res (2015) 38:313-20. doi: 10.1007/s12272-015-0567-x

13. Herst PM, Grasso C, Berridge MV. Metabolic Reprogramming of Mitochondrial Respiration in Metastatic Cancer. Cancer Metastasis Rev (2018) 37:643-53. doi: 10.1007/s10555-018-9769-2

14. Zhao H, Li Y. Cancer Metabolism and Intervention Therapy. Mol Biomedicine (2021) 2:5. doi: 10.1186/s43556-020-00012-1

15. Yang Z, Huang R, Wei X, Yu W, Min Z, Ye M. The SIRT6-AutophagyWarburg Effect Axis in Papillary Thyroid Cancer. Front Oncol (2020) 10:1265. doi: 10.3389/fonc.2020.01265

16. Chen J, Zhou Q, Feng J, Zheng W, Du J, Meng X, et al. Activation of AMPK Promotes Thyroid Cancer Cell Migration Through Its Interaction With PKM2 and $\beta$-Catenin. Life Sci (2019) 239:116877. doi: 10.1016/ j.lfs.2019.116877
MG and PH. All authors contributed to the article and approved the submitted version.

\section{FUNDING}

This work was funded by the National Natural Science Foundation, People's Republic of China (Nos. 82173157, U20A20382, 81872170, 81802673), Natural Science Foundation of Zhejiang Provincial under Grant No.Y22H168220, Chinese Medicine Research Program of Zhejiang Province (No. 2021ZA006), and Zhejiang Medical and Health Science and Technology Project (Nos. 2021KY056 and 2022KY042).

17. Wang R, Cheng Y, Su D, Gong B, He X, Zhou X, et al. Cpt1c Regulated by AMPK Promotes Papillary Thyroid Carcinomas Cells Survival Under Metabolic Stress Conditions. J Cancer (2017) 239:3675-81. doi: 10.7150/ jca. 21148

18. Kishore M, Cheung KCP, Fu H, Bonacina F, Wang G, Coe D, et al Regulatory $\mathrm{T}$ Cell Migration Is Dependent on Glucokinase-Mediated Glycolysis. Immunity (2017) 47:875-89.e10. doi: 10.1016/j.immuni. 2017.10.017

19. Li L, Liang Y, Kang L, Liu Y, Gao S, Chen S, et al. Transcriptional Regulation of the Warburg Effect in Cancer by SIX1. Cancer Cell (2018) 33:368-85.e7. doi: 10.1016/j.ccell.2018.01.010

20. Hensley CT, Faubert B, Yuan Q, Lev-Cohain N, Jin E, Kim J, et al. Metabolic Heterogeneity in Human Lung Tumors. CELL (2016) 164:681-94. doi: 10.1016/j.cell.2015.12.034

21. Christen S, Lorendeau D, Schmieder R, Broekaert D, Metzger K, Veys K, et al. Breast Cancer-Derived Lung Metastases Show Increased Pyruvate Carboxylase-Dependent Anaplerosis. Cell Rep (2016) 17:837-48 doi: 10.1016/j.celrep.2016.09.042

22. Chen J, Lee HJ, Wu X, Huo L, Kim SJ, Xu L, et al. Gain of GlucoseIndependent Growth Upon Metastasis of Breast Cancer Cells to the Brain. Cancer Res (2015) 75:554-65. doi: 10.1158/0008-5472.Can-14-2268

23. Mulvey PFJr., Kelleher JJ, Slingerland DW. Oxidation of Glucose-C14 by Human Thyroid Tissues. Metabolism (1963) 12:829-32.

24. Hengstschläger M, Mudrak I, Wintersberger E, Wawra E. A Common Regulation of Genes Encoding Enzymes of the Deoxynucleotide Metabolism is Lost After Neoplastic Transformation. Cell Growth Differ (1994) 5:1389-94

25. Gao Y, Yang F, Yang XA, Zhang L, Yu H, Cheng X, et al. Mitochondrial Metabolism is Inhibited by the HIF1 $\alpha$-MYC-PGC-1 $\beta$ Axis in BRAF V600E Thyroid Cancer. FEBS J (2019) 286:1420-36. doi: 10.1111/febs.14786

26. Zhou L, Cha G, Chen L, Yang C, Xu D, Ge M. HIF1 $\alpha / P D-L 1$ Axis Mediates Hypoxia-Induced Cell Apoptosis and Tumor Progression in Follicular Thyroid Carcinoma. Onco Targets Ther (2019) 12:6461-70. doi: 10.2147/ ott.S203724

27. Yang Z, Yu W, Huang R, Ye M, Min Z. SIRT6/HIF-1 $\alpha$ Axis Promotes Papillary Thyroid Cancer Progression by Inducing Epithelial-Mesenchymal Transition. Cancer Cell Int (2019) 19:17. doi: 10.1186/s12935-019-0730-4

28. Klaus A, Fathi O, Tatjana TW, Bruno N, Oskar K. Expression of HypoxiaAssociated Protein HIF-1 $\alpha$ in Follicular Thyroid Cancer is Associated With Distant Metastasis. Pathol Oncol Res (2018) 24:289-96. doi: 10.1007/s12253017-0232-4

29. Yu L, Lu M, Jia D, Ma J, Ben-Jacob E, Levine H, et al. Modeling the Genetic Regulation of Cancer Metabolism: Interplay Between Glycolysis and Oxidative Phosphorylation. Cancer Res (2017) 77:1564-74. doi: 10.1158/ 0008-5472.Can-16-2074

30. Matijevic Glavan T, Cipak Gasparovic A, Vérillaud B, Busson P, Pavelic J. Toll-Like Receptor 3 Stimulation Triggers Metabolic Reprogramming in Pharyngeal Cancer Cell Line Through Myc, MAPK, and HIF. Mol Carcinog (2017) 56:1214-26. doi: 10.1002/mc.22584 
31. Choudhry H, Harris AL. Advances in Hypoxia-Inducible Factor Biology. Cell Metab (2018) 27:281-98. doi: 10.1016/j.cmet.2017.10.005

32. Hou X, Shi X, Zhang W, Li D, Hu L, Yang J, et al. LDHA Induces EMT Gene Transcription and Regulates Autophagy to Promote the Metastasis and Tumorigenesis of Papillary Thyroid Carcinoma. Cell Death Dis (2021) 12:347. doi: 10.1038/s41419-021-03641-8

33. Jin L, Chun J, Pan C, Alesi GN, Li D, Magliocca KR, et al. PhosphorylationMediated Activation of LDHA Promotes Cancer Cell Invasion and Tumour Metastasis. Oncogene (2017) 36:3797-806. doi: 10.1038/onc.2017.6

34. Matsuzu K, Segade F, Matsuzu U, Carter A, Bowden DW, Perrier ND. Differential Expression of Glucose Transporters in Normal and Pathologic Thyroid Tissue. Thyroid (2004) 14:806-12. doi: 10.1089/thy.2004.14.806

35. Grabellus F, Nagarajah J, Bockisch A, Schmid KW, Sheu SY. Glucose Transporter 1 Expression, Tumor Proliferation, and Iodine/Glucose Uptake in Thyroid Cancer With Emphasis on Poorly Differentiated Thyroid Carcinoma. Clin Nucl Med (2012) 35:121-7. doi: 10.1097/ RLU.0b013e3182393599

36. Ciampi R, Vivaldi A, Romei C, Del Guerra A, Salvadori P, Cosci B, et al. Expression Analysis of Facilitative Glucose Transporters (Gluts) in Human Thyroid Carcinoma Cell Lines and Primary Tumors. Mol Cell Endocrinol (2008) 291:57-62. doi: 10.1016/j.mce.2008.05.003

37. Samih N, Hovsepian S, Aouani A, Lombardo D, Fayet G. Glut-1 Translocation in FRTL-5 Thyroid Cells: Role of Phosphatidylinositol 3Kinase and N-Glycosylation. Endocrinology (2000) 141:4146-55. doi: 10.1210/endo.141.11.7793

38. Szablewski L. Expression of Glucose Transporters in Cancers. Biochim Biophys Acta (2013) 1835:164-9. doi: 10.1016/j.bbcan.2012.12.004

39. Jóźwiak P, Krześlak A, Pomorski L, Lipińska A. Expression of HypoxiaRelated Glucose Transporters GLUT1 and GLUT3 in Benign, Malignant and Non-Neoplastic Thyroid Lesions. Mol Med Rep (2012) 6:601-6. doi: $10.3892 / \mathrm{mmr} .2012 .969$

40. Chai YJ, Yi JW, Oh SW, Kim YA, Yi KH, Kim JH, et al. Upregulation of SLC2 (GLUT) Family Genes is Related to Poor Survival Outcomes in Papillary Thyroid Carcinoma: Analysis of Data From the Cancer Genome Atlas. Surgery (2017) 12:188-94. doi: 10.1016/j.surg.2016.04.050

41. Valli A, Morotti M, Zois CE, Albers PK, Soga T, Feldinger K, et al. Adaptation to HIF1 $\alpha$ Deletion in Hypoxic Cancer Cells by Upregulation of GLUT14 and Creatine Metabolism. Mol Cancer Res (2019) 17:1531-44. doi: 10.1158/1541-7786.Mcr-18-0315

42. Haber RS, Weiser KR, Pritsker A, Reder I, Burstein DE. GLUT1 Glucose Transporter Expression in Benign and Malignant Thyroid Nodules. Thyroid (1997) 7:363-7. doi: 10.1089/thy.1997.7.363

43. Xue C, Li G, Bao Z, Zhou Z, Li L. Mitochondrial Pyruvate Carrier 1: A Novel Prognostic Biomarker That Predicts Favourable Patient Survival in Cancer. Cancer Cell Int (2021) 21:288. doi: 10.1186/s12935-021-01996-8

44. Cairns RA, Harris IS, Mak TW. Regulation of Cancer Cell Metabolism. Nat Rev Cancer (2011) 11:85-95. doi: 10.1038/nrc2981

45. Nahm JH, Kim HM, Koo JS. Glycolysis-Related Protein Expression in Thyroid Cancer. Tumour Biol (2017) 39:1010428317695922. doi: 10.1177/ 1010428317695922

46. Hooft L, van der Veldt AA, Hoekstra OS, Boers M, Molthoff CF, van Diest PJ. Hexokinase III, Cyclin a and Galectin-3 are Overexpressed in Malignant Follicular Thyroid Nodules. Clin Endocrinol (Oxf) (2008) 68:252-7. doi: 10.1111/j.1365-2265.2007.03031.x

47. Huang J, Gao W, Liu H, Yin G, Duan H, Huang Z, et al. Up-Regulated ANP32E Promotes the Thyroid Carcinoma Cell Proliferation and Migration via Activating AKT/Mtor/HK2-Mediated Glycolysis. Gene (2020) 750:144681. doi: 10.1016/j.gene.2020.144681

48. Feng C, Gao Y, Wang C, Yu X, Zhang W, Guan H, et al. Aberrant Overexpression of Pyruvate Kinase M2 Is Associated With Aggressive Tumor Features and the BRAF Mutation in Papillary Thyroid Cancer. J Clin Endocrinol Metab (2013) 98:E1524-33. doi: 10.1210/jc.2012-4258

49. Strickaert A, Corbet C, Spinette SA, Craciun L, Dom G, Andry G, et al. Reprogramming of Energy Metabolism: Increased Expression and Roles of Pyruvate Carboxylase in Papillary Thyroid Cancer. Thyroid (2019) 29:84557. doi: $10.1089 /$ thy.2018.0435

50. Verhagen JN, van der Heijden MC, de Jong-van Dijken J, Rijksen G, der Kinderen PJ, van Unnik JA, et al. Pyruvate Kinase in Normal Human Thyroid
Tissue and Thyroid Neoplasms. Cancer (1985) 55:142-8. doi: 10.1002/1097-0142 (19850101) 55:1<142::aid-cncr2820550122>3.0.co;2-x

51. Hosios AM, Hecht VC, Danai LV, Johnson MO, Rathmell JC, Steinhauser ML, et al. Amino Acids Rather Than Glucose Account for the Majority of Cell Mass in Proliferating Mammalian Cells. Dev Cell (2016) 36:540-9. doi: 10.1016/j.devcel.2016.02.012

52. Zhang J, Pavlova NN, Thompson CB. Cancer Cell Metabolism: The Essential Role of the Nonessential Amino Acid, Glutamine. EMBO J (2017) 36:130215. doi: $10.15252 / \mathrm{embj} .201696151$

53. Kodama M, Oshikawa K, Shimizu H, Yoshioka S, Takahashi M, Izumi Y, et al. A Shift in Glutamine Nitrogen Metabolism Contributes to the Malignant Progression of Cancer. Nat Commun (2020) 11:1320. doi: 10.1038/s41467-020-15136-9

54. Altman BJ, Stine ZE, Dang CV. From Krebs to Clinic: Glutamine Metabolism to Cancer Therapy. Nat Rev Cancer (2016) 16:619-34. doi: $10.1038 /$ nrc.2016.71

55. Cluntun AA, Lukey MJ, Cerione RA, Locasale JW. Glutamine Metabolism in Cancer: Understanding the Heterogeneity. Trends Cancer (2017) 3:169-80. doi: 10.1016/j.trecan.2017.01.005

56. Chen Z, Lin J, Feng S, Chen X, Huang H, Wang C, et al. SIRT4 Inhibits the Proliferation, Migration, and Invasion Abilities of Thyroid Cancer Cells by Inhibiting Glutamine Metabolism. Onco Targets Ther (2019) 12:2397-408. doi: $10.2147 /$ ott.S189536

57. Kim HM, Lee YK, Koo JS. Expression of Glutamine Metabolism-Related Proteins in Thyroid Cancer. Oncotarget (2016) 7:53628-41. doi: 10.18632/ oncotarget.10682

58. Cha YJ, Jang H, Koo JS. Expression of Glutamine Metabolism-Related Proteins in Hürthle Cell Neoplasm of Thyroid: Comparison With Follicular Neoplasm. Histol Histopathol (2019) 34:167-74. doi: 10.14670/hh-18-036

59. Gebregiworgis T, Purohit V, Shukla SK, Tadros S, Chaika NV, Abrego J, et al. Glucose Limitation Alters Glutamine Metabolism in MUC1Overexpressing Pancreatic Cancer Cells. J Proteome Res (2017) 16:353646. doi: 10.1021 /acs.jproteome.7b00246

60. Sun WY, Kim HM, Jung WH, Koo JS. Expression of Serine/Glycine MetabolismRelated Proteins is Different According to the Thyroid Cancer Subtype. J Transl Med (2016) 14:168. doi: 10.1186/s12967-016-0915-8

61. Zhao M, Bu Y, Feng J, Zhang H, Chen Y, Yang G, et al. SPIN1 Triggers Abnormal Lipid Metabolism and Enhances Tumor Growth in Liver Cancer. Cancer Lett (2020) 470:54-63. doi: 10.1016/j.canlet.2019.11.032

62. Yi M, Li J, Chen S, Cai J, Ban Y, Peng Q, et al. Emerging Role of Lipid Metabolism Alterations in Cancer Stem Cells. J Exp Clin Cancer Res (2018) 16:118. doi: 10.1186/s13046-018-0784-5

63. Röhrig F, Schulze A. The Multifaceted Roles of Fatty Acid Synthesis in Cancer. Nat Rev Cancer (2016) 16:732-49. doi: 10.1038/nrc.2016.89

64. Mossmann D, Park S, Hall MN. Mtor Signalling and Cellular Metabolism are Mutual Determinants in Cancer. Nat Rev Cancer (2018) 18:744-57. doi: 10.1038/s41568-018-0074-8

65. Luo X, Cheng C, Tan Z, Li N, Tang M, Yang L, et al. Emerging Roles of Lipid Metabolism in Cancer Metastasis. Mol Cancer (2017) 16:76. doi: 10.1186/ s12943-017-0646-3

66. Li H, Feng Z, He ML. Lipid Metabolism Alteration Contributes to and Maintains the Properties of Cancer Stem Cells. Theranostics (2020) 10:705369. doi: 10.7150/thno.41388

67. Cheng C, Geng F, Cheng X, Guo D. Lipid Metabolism Reprogramming and its Potential Targets in Cancer. Cancer Commun (Lond) (2018) 38:27. doi: 10.1186/s40880-018-0301-4

68. Liao T, Wang YJ, Hu JQ, Wang Y, Han LT, Ma B, et al. Histone Methyltransferase KMT5A Gene Modulates Oncogenesis and Lipid Metabolism of Papillary Thyroid Cancer In Vitro. Oncol Rep (2018) 39:2185-92. doi: 10.3892/or.2018.6295

69. Liu H, Liu JY, Wu X, Zhang JT. Biochemistry, Molecular Biology, and Pharmacology of Fatty Acid Synthase, an Emerging Therapeutic Target and Diagnosis/Prognosis Marker. Int J Biochem Mol Biol (2010) 1:69-89.

70. Fantin VR, St-Pierre J, Leder P. Attenuation of LDH-a Expression Uncovers a Link Between Glycolysis, Mitochondrial Physiology, and Tumor Maintenance. Cancer Cell (2006) 9:425-34. doi: 10.1016/j.ccr.2006.04.023

71. Zhang C, Liu J, Huang G, Zhao Y, Yue X, Wu H, et al. Cullin3-KLHL25 Ubiquitin Ligase Targets ACLY for Degradation to Inhibit Lipid Synthesis 
and Tumor Progression. Genes Dev (2016) 30:1956-70. doi: 10.1101/ gad.283283.116

72. Svensson RU, Parker SJ, Eichner LJ, Kolar MJ, Wallace M, Brun SN, et al. Inhibition of Acetyl-Coa Carboxylase Suppresses Fatty Acid Synthesis and Tumor Growth of Non-Small-Cell Lung Cancer in Preclinical Models. Nat Med (2016) 22:1108-19. doi: 10.1038/nm.4181

73. Rios Garcia M, Steinbauer B, Srivastava K, Singhal M, Mattijssen F, Maida A, et al. Acetyl-Coa Carboxylase 1-Dependent Protein Acetylation Controls Breast Cancer Metastasis and Recurrence. Cell Metab (2017) 26:842-55.e5. doi: 10.1016/j.cmet.2017.09.018

74. Nwosu ZC, Battello N, Rothley M, Piorońska W, Sitek B, Ebert MP, et al. Liver Cancer Cell Lines Distinctly Mimic the Metabolic Gene Expression Pattern of the Corresponding Human Tumours. J Exp Clin Cancer Res (2018) 37:211. doi: 10.1186/s13046-018-0872-6

75. Lally JSV, Ghoshal S, DePeralta DK, Moaven O, Wei L, Masia R, et al. Inhibition of Acetyl-Coa Carboxylase by Phosphorylation or the Inhibitor ND-654 Suppresses Lipogenesis and Hepatocellular Carcinoma. Cell Metab (2019) 29:174-82.e5. doi: 10.1016/j.cmet.2018.08.020

76. Kapadia B, Nanaji NM, Bhalla K, Bhandary B, Lapidus R, Beheshti A, et al. Fatty Acid Synthase Induced S6Kinase Facilitates USP11-Eif4b Complex Formation for Sustained Oncogenic Translation in DLBCL. Nat Commun (2018) 9:829. doi: 10.1038/s41467-018-03028-y

77. Gu L, Zhu Y, Lin X, Lu B, Zhou X, Zhou F, et al. The Ikkß-USP30-ACLY Axis Controls Lipogenesis and Tumorigenesis. Hepatology (2021) 73:16074. doi: 10.1002/hep.31249

78. Gouw AM, Margulis K, Liu NS, Raman SJ, Mancuso A, Toal GG, et al. The MYC Oncogene Cooperates With Sterol-Regulated Element-Binding Protein to Regulate Lipogenesis Essential for Neoplastic Growth. Cell Metab (2019) 30:556-72.e5. doi: 10.1016/j.cmet.2019.07.012

79. Corbet C, Pinto A, Martherus R, Santiago de Jesus JP, Polet F, Feron O. Acidosis Drives the Reprogramming of Fatty Acid Metabolism in Cancer Cells Through Changes in Mitochondrial and Histone Acetylation. Cell Metab (2016) 24:311-23. doi: 10.1016/j.cmet.2016.07.003

80. Che L, Chi W, Qiao Y, Zhang J, Song X, Liu Y, et al. Cholesterol Biosynthesis Supports the Growth of Hepatocarcinoma Lesions Depleted of Fatty Acid Synthase in Mice and Humans. Gut (2020) 69:177-86. doi: 10.1136/gutjnl2018-317581

81. Bort A, Sánchez BG, de Miguel I, Mateos-Gómez PA, Diaz-Laviada I. Dysregulated Lipid Metabolism in Hepatocellular Carcinoma Cancer Stem Cells. Mol Biol Rep (2020) 47:2635-47. doi: 10.1007/s11033-020-05352-3

82. Ali A, Levantini E, Teo JT, Goggi J, Clohessy JG, Wu CS, et al. Fatty Acid Synthase Mediates EGFR Palmitoylation in EGFR Mutated Non-Small Cell Lung Cancer. EMBO Mol Med (2018) 10. doi: 10.15252/emmm.201708313

83. Abbassi-Ghadi N, Antonowicz SS, McKenzie JS, Kumar S, Huang J, Jones EA, et al. De Novo Lipogenesis Alters the Phospholipidome of Esophageal Adenocarcinoma. Cancer Res (2020) 80:2764-74. doi: 10.1158/00085472.Can-19-4035

84. Xu M, Sun T, Wen S, Zhang T, Wang X, Cao Y, et al. Characteristics of Lipid Metabolism-Related Gene Expression-Based Molecular Subtype in Papillary Thyroid Cancer. Acta Biochim Biophys Sin (Shanghai) (2020) 52:1166-70. doi: 10.1093/abbs/gmaa092

85. Leng J, Guan Q, Sun T, Wu Y, Cao Y, Guo Y. Application of Isotope-Based Carboxy Group Derivatization in LC-MS/MS Analysis of Tissue Free-Fatty Acids for Thyroid Carcinoma. J Pharm BioMed Anal (2013) 84:256-62. doi: 10.1016/j.jpba.2013.06.004

86. Uddin S, Siraj AK, Al-Rasheed M, Ahmed M, Bu R, Myers JN, et al. Fatty Acid Synthase and AKT Pathway Signaling in a Subset of Papillary Thyroid Cancers. J Clin Endocrinol Metab (2008) 93:4088-97. doi: 10.1210/jc.2008-0503

87. Sekiguchi M, Shiroko Y, Arai T, Kishino T, Sugawara I, Kusakabe T, et al. Biological Characteristics and Chemosensitivity Profile of Four Human Anaplastic Thyroid Carcinoma Cell Lines. BioMed Pharmacother (2001) 55:466-74. doi: 10.1016/s0753-3322(01)00087-7

88. Liu J, Brown RE. Immunohistochemical Expressions of Fatty Acid Synthase and Phosphorylated C-Met in Thyroid Carcinomas of Follicular Origin. Int $J$ Clin Exp Pathol (2011) 4:755-64.

89. Munir R, Lisec J, Swinnen JV, Zaidi N. Lipid Metabolism in Cancer Cells Under Metabolic Stress. Br J Cancer (2019) 120:1090-8. doi: 10.1038/ s41416-019-0451-4
90. Valvo V, Iesato A, Kavanagh TR, Priolo C, Zsengeller Z, Pontecorvi A, et al. Fine-Tuning Lipid Metabolism by Targeting Mitochondria-Associated Acetyl-Coa-Carboxylase 2 in BRAF(V600E) Papillary Thyroid Carcinoma. Thyroid (2021) 31:1335-58. doi: 10.1089/thy.2020.0311

91. von Roemeling CA, Marlow LA, Pinkerton AB, Crist A, Miller J, Tun HW, et al. Aberrant Lipid Me\{Von Roemeling, 2015 \#353\}Tabolism in Anaplastic Thyroid Carcinoma Reveals Stearoyl Coa Desaturase 1 as a Novel Therapeutic Target. J Clin Endocrinol Metab (2015) 100:E697-709. doi: 10.1210/jc.2014-2764

92. Guo S, Wang Y, Zhou D, Li Z. Significantly Increased Monounsaturated Lipids Relative to Polyunsaturated Lipids in Six Types of Cancer Microenvironment are Observed by Mass Spectrometry Imaging. Sci Rep (2014) 4:5959. doi: 10.1038/srep05959

93. Turi Z, Lacey M, Mistrik M, Moudry P. Impaired Ribosome Biogenesis: Mechanisms and Relevance to Cancer and Aging. Aging (Albany NY) (2019) 11:2512-40. doi: 10.18632/aging.101922

94. Prakash V, Carson BB, Feenstra JM, Dass RA, Sekyrova P, Hoshino A, et al. Ribosome Biogenesis During Cell Cycle Arrest Fuels EMT in Development and Disease. Nat Commun (2019) 10:2110. doi: 10.1038/s41467-01910100-8

95. Penzo M, Montanaro L, Treré D, Derenzini M. The Ribosome BiogenesisCancer Connection. Cells (2019) 8. doi: 10.3390/cells8010055

96. Pelletier J, Thomas G, Volarević S. Ribosome Biogenesis in Cancer: New Players and Therapeutic Avenues. Nat Rev Cancer (2018) 18:51-63. doi: 10.1038/nrc.2017.104

97. Kim DS, Camacho CV, Nagari A, Malladi VS, Challa S, Kraus WL. Activation of PARP-1 by Snornas Controls Ribosome Biogenesis and Cell Growth via the RNA Helicase DDX21. Mol Cell (2019) 75:1270-85.e14. doi: 10.1016/j.molcel.2019.06.020

98. Catez F, Dalla Venezia N, Marcel V, Zorbas C, Lafontaine DLJ, Diaz JJ. Ribosome Biogenesis: An Emerging Druggable Pathway for Cancer Therapeutics. Biochem Pharmacol (2019) 175:74-81. doi: 10.1016/ j.bcp.2018.11.014

99. Saiselet M, Floor S, Tarabichi M, Dom G, Hébrant A, van Staveren WC, et al. Thyroid Cancer Cell Lines: An Overview. Front Endocrinol (Lausanne) (2012) 3:133. doi: 10.3389/fendo.2012.00133

100. Jeong S, Kim IK, Kim H, Choi MJ, Lee J, Jo YS. Liver X Receptor $\beta$ Related to Tumor Progression and Ribosome Gene Expression in Papillary Thyroid Cancer. Endocrinol Metab (Seoul) (2020) 35:656-68. doi: 10.3803/EnM.2020.667

101. Wang Y, Bai C, Ruan Y, Liu M, Chu Q, Qiu L, et al. Coordinative Metabolism of Glutamine Carbon and Nitrogen in Proliferating Cancer Cells Under Hypoxia. Nat Commun (2019) 10:201. doi: 10.1038/s41467-018-08033-9

102. Tardito S, Oudin A, Ahmed SU, Fack F, Keunen O, Zheng L, et al. Glutamine Synthetase Activity Fuels Nucleotide Biosynthesis and Supports Growth of Glutamine-Restricted Glioblastoma. Nat Cell Biol (2015) 17:1556-68. doi: $10.1038 / \mathrm{ncb} 3272$

103. Kodama M, Nakayama KI. A Second Warburg-Like Effect in Cancer Metabolism: The Metabolic Shift of Glutamine-Derived Nitrogen: A Shift in Glutamine-Derived Nitrogen Metabolism From Glutaminolysis to De Novo Nucleotide Biosynthesis Contributes to Malignant Evolution of Cancer. BIOESSAYS (2020) 42:e2000169. doi: 10.1002/bies.202000169

104. Fu S, Li Z, Xiao L, Hu W, Zhang L, Xie B, et al. Glutamine Synthetase Promotes Radiation Resistance via Facilitating Nucleotide Metabolism and Subsequent DNA Damage Repair. Cell Rep (2019) 28:1136-43.e4. doi: 10.1016/j.celrep.2019.07.002

105. Bott AJ, Shen J, Tonelli C, Zhan L, Sivaram N, Jiang YP, et al. Glutamine Anabolism Plays a Critical Role in Pancreatic Cancer by Coupling Carbon and Nitrogen Metabolism. Cell Rep (2019) 29:1287-98.e6. doi: 10.1016/ j.celrep.2019.09.056

106. Lv Y, Wang X, Li X, Xu G, Bai Y, Wu J, et al. Nucleotide De Novo Synthesis Increases Breast Cancer Stemness and Metastasis via Cgmp-PKG-MAPK Signaling Pathway. PloS Biol (2020) 18:e3000872. doi: 10.1371/ journal.pbio. 3000872

107. Chan EM, Shibue T, McFarland JM, Gaeta B, Ghandi M, Dumont N, et al. WRN Helicase is a Synthetic Lethal Target in Microsatellite Unstable Cancers. NATURE (2019) 568:551-6. doi: 10.1038/s41586-019-1102-x

108. Robb R, Yang L, Shen C, Wolfe AR, Webb A, Zhang X, et al. Inhibiting BRAF Oncogene-Mediated Radioresistance Effectively Radiosensitizes BRAF 
(V600E)-Mutant Thyroid Cancer Cells by Constraining DNA DoubleStrand Break Repair. Clin Cancer Res (2019) 25:4749-60. doi: 10.1158/ 1078-0432.Ccr-18-3625

109. Cabanillas ME, Ferrarotto R, Garden AS, Ahmed S, Busaidy NL, Dadu R, et al. Neoadjuvant BRAF- and Immune-Directed Therapy for Anaplastic Thyroid Carcinoma. THYROID (2018) 28:945-51. doi: 10.1089/thy.2018.0060

110. Trybek T, Walczyk A, Gasior-Perczak D, Pałyga I, Mikina E, Kowalik A, et al. Impact of BRAF V600E and TERT Promoter Mutations on Response to Therapy in Papillary Thyroid Cancer. Endcrinology (2019) 160:2328-38. doi: 10.1210/en.2019-00315

111. Panebianco F, Nikitski AV, Nikiforova MN, Nikiforov YE. Spectrum of TERT Promoter Mutations and Mechanisms of Activation in Thyroid Cancer. Cancer Med (2019) 8:5831-9. doi: 10.1002/cam4.2467

112. Melo M, Gaspar da Rocha A, Batista R, Vinagre J, Martins MJ, Costa G, et al. TERT, BRAF, and NRAS in Primary Thyroid Cancer and Metastatic Disease. J Clin Endocrinol Metab (2017) 102:1898-907. doi: 10.1210/jc.2016-2785

113. Chen M, Shen M, Li Y, Liu C, Zhou K, Hu W, et al. GC-MS-Based Metabolomic Analysis of Human Papillary Thyroid Carcinoma Tissue. Int J Mol Med (2015) 36:1607-14. doi: 10.3892/ijmm.2015.2368

114. Cham CM, Gajewski TF. Glucose Availability Regulates IFN-Gamma Production and P70s6 Kinase Activation in CD8+ Effector T Cells. J Immunol (2005) 174:4670-7. doi: 10.4049/jimmunol.174.8.4670

115. Chang CH, Curtis JD, Maggi LBJr., Faubert B, Villarino AV, O'Sullivan D, et al. Posttranscriptional Control of T Cell Effector Function by Aerobic Glycolysis. CELL (2013) 153:1239-51. doi: 10.1016/j.cell.2013.05.016

116. Elia I, Haigis MC. Metabolites and the Tumour Microenvironment: From Cellular Mechanisms to Systemic Metabolism. Nat Metab (2021) 3:21-32. doi: 10.1038/s42255-020-00317-z

117. Leone RD, Zhao L, Englert JM, Sun IM, Oh MH, Sun IH, et al. Glutamine Blockade Induces Divergent Metabolic Programs to Overcome Tumor Immune Evasion. Science (2019) 366:1013-21. doi: 10.1126/science.aav2588

118. Moretti S, Menicali E, Voce P, Morelli S, Cantarelli S, Sponziello M, et al. Indoleamine 2,3-Dioxygenase 1 (IDO1) is Up-Regulated in Thyroid Carcinoma and Drives the Development of an Immunosuppressant Tumor Microenvironment. J Clin Endocrinol Metab (2014) 99:E832-40. doi: 10.1210/jc.2013-3351

119. Park A, Yang Y, Lee Y, Kim MS, Park YJ, Jung H, et al. Indoleamine-2,3Dioxygenase in Thyroid Cancer Cells Suppresses Natural Killer Cell Function by Inhibiting NKG2D and Nkp46 Expression via STAT Signaling Pathways. J Clin Med (2019) 8. doi: 10.3390/jcm8060842

120. Chu R, Liu SY, Vlantis AC, van Hasselt CA, Ng EK, Fan MD, et al. Inhibition of Foxp3 in Cancer Cells Induces Apoptosis of Thyroid Cancer Cells. Mol Cell Endocrinol (2015) 399:228-34. doi: 10.1016/j.mce.2014.10.006

121. Ivashkiv LB. The Hypoxia-Lactate Axis Tempers Inflammation. Nat Rev Immunol (2020) 20:85-6. doi: 10.1038/s41577-019-0259-8

122. Arts RJ, Plantinga TS, Tuit S, Ulas T, Heinhuis B, Tesselaar M, et al. Transcriptional and Metabolic Reprogramming Induce an Inflammatory Phenotype in Non-Medullary Thyroid Carcinoma-Induced Macrophages. OncoImmunology (2016) 5:e1229725. doi: 10.1080/ 2162402x.2016.1229725

123. Brand A, Singer K, Koehl GE, Kolitzus M, Schoenhammer G, Thiel A, et al. LDHA-Associated Lactic Acid Production Blunts Tumor Immunosurveillance by $\mathrm{T}$ and NK Cells. Cell Metab (2016) 24:657-71. doi: 10.1016/j.cmet.2016.08.011

124. Cantelmo AR, Conradi LC, Brajic A, Goveia J, Kalucka J, Pircher A, et al. Inhibition of the Glycolytic Activator PFKFB3 in Endothelium Induces Tumor Vessel Normalization, Impairs Metastasis, and Improves Chemotherapy. Cancer Cell (2016) 30:968-85. doi: 10.1016/j.ccell.2016.10.006

125. Colegio OR, Chu NQ, Szabo AL, Chu T, Rhebergen AM, Jairam V, et al. Functional Polarization of Tumour-Associated Macrophages by TumourDerived Lactic Acid. Nature (2014) 513:559-63. doi: 10.1038/nature13490

126. Curry JM, Tuluc M, Whitaker-Menezes D, Ames JA, Anantharaman A, Butera A, et al. Cancer Metabolism, Stemness and Tumor Recurrence: MCT1 and MCT4 are Functional Biomarkers of Metabolic Symbiosis in Head and Neck Cancer. Cell Cycle (2013) 12:1371-84. doi: 10.4161/cc.24092

127. Curry JM, Tassone P, Cotzia P, Sprandio J, Luginbuhl A, Cognetti DM, et al. Multicompartment Metabolism in Papillary Thyroid Cancer. Laryngoscope (2016) 126:2410-8. doi: 10.1002/lary.25799
128. Bertero T, Oldham WM, Grasset EM, Bourget I, Boulter E, Pisano S, et al. Tumor-Stroma Mechanics Coordinate Amino Acid Availability to Sustain Tumor Growth and Malignancy. Cell Metab (2019) 29:124-40.e10. doi: 10.1016/j.cmet.2018.09.012

129. Mestre-Farrera A, Bruch-Oms M, Peña R, Rodríguez-Morató J, AlbaCastellón L, Comerma L, et al. Glutamine-Directed Migration of CancerActivated Fibroblasts Facilitates Epithelial Tumor Invasion. Cancer Res (2021) 81:438-51. doi: 10.1158/0008-5472.Can-20-0622

130. Sherman MH, Yu RT, Tseng TW, Sousa CM, Liu S, Truitt ML, et al. Stromal Cues Regulate the Pancreatic Cancer Epigenome and Metabolome. Proc Natl Acad Sci USA (2017) 114:1129-34. doi: 10.1073/pnas.1620164114

131. Cadamuro M, Brivio S, Mertens J, Vismara M, Moncsek A, Milani C, et al. Platelet-Derived Growth Factor-D Enables Liver Myofibroblasts to Promote Tumor Lymphangiogenesis in Cholangiocarcinoma. J Hepatol (2019) 70:700-9. doi: 10.1016/j.jhep.2018.12.004

132. Cruz-Bermúdez A, Laza-Briviesca R, Vicente-Blanco RJ, García-Grande A, Coronado MJ, Laine-Menéndez S, et al. Cancer-Associated Fibroblasts Modify Lung Cancer Metabolism Involving ROS and TGF- $\beta$ Signaling. Free Radic Biol Med (2019) 130:163-73. doi: 10.1016/j.freeradbiomed.2018.10.450

133. Fozzatti L, Alamino VA, Park S, Giusiano L, Volpini X, Zhao L, et al. Interplay of Fibroblasts With Anaplastic Tumor Cells Promotes Follicular Thyroid Cancer Progression. Sci Rep (2019) 9:8028. doi: 10.1038/s41598019-44361-6

134. Rabold K, Aschenbrenner A, Thiele C, Boahen CK, Schiltmans A, Smit JWA, et al. Enhanced Lipid Biosynthesis in Human Tumor-Induced Macrophages Contributes to Their Protumoral Characteristics. J Immunother Cancer (2020) 8. doi: 10.1136/jitc-2020-000638

135. Schönberger J, Rüschoff J, Grimm D, Marienhagen J, Rümmele P, Meyringer R, et al. Glucose Transporter 1 Gene Expression is Related to Thyroid Neoplasms With an Unfavorable Prognosis: An Immunohistochemical Study. THYROID (2002) 12:747-54. doi: 10.1089/105072502760339307

136. Johnson JM, Lai SY, Cotzia P, Cognetti D, Luginbuhl A, Pribitkin EA, et al. Mitochondrial Metabolism as a Treatment Target in Anaplastic Thyroid Cancer. Semin Oncol (2015) 42:915-22. doi: 10.1053/j.seminoncol. 2015.09.025

137. Matsuzu K, Segade F, Wong M, Clark OH, Perrier ND, Bowden DW. Glucose Transporters in the Thyroid. Thyroid (2005) 15:545-50. doi: $10.1089 /$ thy.2005.15.545

138. Yang H, Zhong JT, Zhou SH, Han HM. Roles of GLUT-1 and HK-II Expression in the Biological Behavior of Head and Neck Cancer. Oncotarget (2019) 10:3066-83. doi: 10.18632/oncotarget.24684

139. Suh HY, Choi H, Paeng JC, Cheon GJ, Chung JK, Kang KW. Comprehensive Gene Expression Analysis for Exploring the Association Between Glucose Metabolism and Differentiation of Thyroid Cancer. BMC Cancer (2019) 19:1260. doi: 10.1186/s12885-019-6482-7

140. Kim S, Chung JK, Min HS, Kang JH, Park DJ, Jeong JM, et al. Expression Patterns of Glucose Transporter-1 Gene and Thyroid Specific Genes in Human Papillary Thyroid Carcinoma. Nucl Med Mol Imaging (2014) 48:917. doi: 10.1007/s13139-013-0249-x

141. Huang FQ, Li J, Jiang L, Wang FX, Alolga RN, Wang MJ, et al. Serum-Plasma Matched Metabolomics for Comprehensive Characterization of Benign Thyroid Nodule and Papillary Thyroid Carcinoma. Int J Cancer (2019) 144:868-76. doi: 10.1002/ijc.31925

142. Ryu HS, Park YS, Park HJ, Chung YR, Yom CK, Ahn SH, et al. Expression of Indoleamine 2,3-Dioxygenase and Infiltration of FOXP3+ Regulatory T Cells are Associated With Aggressive Features of Papillary Thyroid Microcarcinoma. Thyroid (2014) 42:1232-40. doi: 10.1089/thy.2013.0423

143. Hsieh IS, Gopula B, Chou CC, Wu HY, Chang GD, Wu WJ, et al. Development of Novel Irreversible Pyruvate Kinase M2 Inhibitors. J Med Chem (2019) 62:8497-510. doi: 10.1021/acs.jmedchem.9b00763

144. Vangapandu HV, Alston B, Morse J, Ayres ML, Wierda WG, Keating MJ, et al. Biological and Metabolic Effects of IACS-010759, an Oxphos Inhibitor, on Chronic Lymphocytic Leukemia Cells. Oncotarget (2018) 9:24980-91. doi: $10.18632 /$ oncotarget.25166

145. Bizjak M, Malavašič P, Dolinar K, Pohar J, Pirkmajer S, Pavlin M. Combined Treatment With Metformin and 2-Deoxy Glucose Induces Detachment of Viable MDA-MB-231 Breast Cancer Cells. vitro Sci Rep (2017) 7:1761. doi: $10.1038 / \mathrm{s} 41598-017-01801-5$ 
146. Jones AT, Narov K, Yang J, Sampson JR, Shen MH. Efficacy of Dual Inhibition of Glycolysis and Glutaminolysis for Therapy of Renal Lesions in Tsc2(+/-) Mice. Neoplasia (2019) 21:230-8. doi: 10.1016/j.neo.2018.12.003

147. Sun Y, Bandi M, Lofton T, Smith M, Bristow CA, Carugo A, et al. Functional Genomics Reveals Synthetic Lethality Between Phosphogluconate Dehydrogenase and Oxidative Phosphorylation. Cell Rep (2019) 26:46982.e5. doi: 10.1016/j.celrep.2018.12.043

148. DeWaal D, Nogueira V, Terry AR, Patra KC, Jeon SM, Guzman G, et al. Hexokinase-2 Depletion Inhibits Glycolysis and Induces Oxidative Phosphorylation in Hepatocellular Carcinoma and Sensitizes to Metformin. Nat Commun (2018) 9:446. doi: 10.1038/s41467-017-02733-4

149. Shimada N, Takasawa R, Tanuma SI. Interdependence of GLO I and PKM2 in the Metabolic Shift to Escape Apoptosis in GLO I-Dependent Cancer Cells. Arch Biochem Biophys (2018) 638:1-7. doi: 10.1016/j.abb.2017.12.008

150. Zhao B, Aggarwal A, Marshall JA, Barletta JA, Kijewski MF, Lorch JH, et al. Glycolytic Inhibition With 3-Bromopyruvate Suppresses Tumor Growth and Improves Survival in a Murine Model of Anaplastic Thyroid Cancer. Surgery (2021). doi: 10.1016/j.surg.2021.05.055

151. Wang SY, Wei YH, Shieh DB, Lin LL, Cheng SP, Wang PW, et al. 2-DeoxyD-Glucose can Complement Doxorubicin and Sorafenib to Suppress the Growth of Papillary Thyroid Carcinoma Cells. PloS One (2015) 10:e0130959. doi: 10.1371/journal.pone.0130959

152. Sobhakumari A, Orcutt KP, Love-Homan L, Kowalski CE, Parsons AD, Knudson CM, et al. 2-Deoxy-D-Glucose Suppresses the in Vivo Antitumor Efficacy of Erlotinib in Head and Neck Squamous Cell Carcinoma Cells. Oncol Res (2016) 24:55-64. doi: 10.3727/096504016x14586627440192

153. Sandulache VC, Skinner HD, Wang Y, Chen Y, Dodge CT, Ow TJ, et al. Glycolytic Inhibition Alters Anaplastic Thyroid Carcinoma Tumor Metabolism and Improves Response to Conventional Chemotherapy and Radiation. Mol Cancer Ther (2012) 11:1373-80. doi: 10.1158/15357163.Mct-12-0041

154. Robbins RJ, Wan Q, Grewal RK, Reibke R, Gonen M, Strauss HW, et al. RealTime Prognosis for Metastatic Thyroid Carcinoma Based on 2-[18F]Fluoro2-Deoxy-D-Glucose-Positron Emission Tomography Scanning. J Clin Endocrinol Metab (2006) 91:498-505. doi: 10.1210/jc.2005-1534

155. Li J, Eu JQ, Kong LR, Wang L, Lim YC, Goh BC, et al. Targeting Metabolism in Cancer Cells and the Tumour Microenvironment for Cancer Therapy. Molecules (2020) 25. doi: 10.3390/molecules25204831

156. Nancolas B, Guo L, Zhou R, Nath K, Nelson DS, Leeper DB, et al. The AntiTumour Agent Lonidamine is a Potent Inhibitor of the Mitochondrial Pyruvate Carrier and Plasma Membrane Monocarboxylate Transporters. Biochem J (2016) 473:929-36. doi: 10.1042/bj20151120

157. Berruti A, Bitossi R, Gorzegno G, Bottini A, Alquati P, De Matteis A, et al. Time to Progression in Metastatic Breast Cancer Patients Treated With Epirubicin is Not Improved by the Addition of Either Cisplatin or Lonidamine: Final Results of a Phase III Study With a Factorial Design. J Clin Oncol (2002) 20:4150-9. doi: 10.1200/jco.2002.08.012

158. Wagner M, Wuest M, Lopez-Campistrous A, Glubrecht D, Dufour J, Jans HS, et al. Tyrosine Kinase Inhibitor Therapy and Metabolic Remodelling in Papillary Thyroid Cancer. Endocr Relat Cancer (2020) 27:495-507. doi: 10.1530/erc-20-0135

159. Chen Y, Maniakas A, Tan L, Cui M, Le X, Niedzielski JS, et al. Development of a Rational Strategy for Integration of Lactate Dehydrogenase a Suppression Into Therapeutic Algorithms for Head and Neck Cancer. $\mathrm{Br} \mathrm{J}$ Cancer (2021) 124:1670-9. doi: 10.1038/s41416-021-01297-x

160. Van Poznak C, Seidman AD, Reidenberg MM, Moasser MM, Sklarin N, Van Zee K, et al. Oral Gossypol in the Treatment of Patients With Refractory Metastatic Breast Cancer: A Phase I/II Clinical Trial. Breast Cancer Res Treat (2001) 66:239-48. doi: 10.1023/a:1010686204736

161. Rellinger EJ, Craig BT, Alvarez AL, Dusek HL, Kim KW, Qiao J, et al. FX11 Inhibits Aerobic Glycolysis and Growth of Neuroblastoma Cells. SURGERY (2017) 161:747-52. doi: 10.1016/j.surg.2016.09.009

162. Zhao Z, Han F, Yang S, Wu J, Zhan W. Oxamate-Mediated Inhibition of Lactate Dehydrogenase Induces Protective Autophagy in Gastric Cancer Cells: Involvement of the Akt-Mtor Signaling Pathway. Cancer Lett (2015) 358:17-26. doi: 10.1016/j.canlet.2014.11.046

163. Pieters R, Appel I, Kuehnel HJ, Tetzlaff-Fohr I, Pichlmeier U, van der Vaart I, et al. Pharmacokinetics, Pharmacodynamics, Efficacy, and Safety of a New
Recombinant Asparaginase Preparation in Children With Previously Untreated Acute Lymphoblastic Leukemia: A Randomized Phase 2 Clinical Trial. Blood (2008) 112:4832-8. doi: 10.1182/blood-2008-04-149443

164. Zhai L, Spranger S, Binder DC, Gritsina G, Lauing KL, Giles FJ, et al. Molecular Pathways: Targeting IDO1 and Other Tryptophan Dioxygenases for Cancer Immunotherapy. Clin Cancer Res (2015) 21:5427-33. doi: 10.1158/1078-0432.Ccr-15-0420

165. Joyce JA, Fearon DT. T Cell Exclusion, Immune Privilege, and the Tumor Microenvironment. SCIENCE (2015) 348:74-80. doi: 10.1126/science.aaa6204

166. Glazer ES, Piccirillo M, Albino V, Di Giacomo R, Palaia R, Mastro AA, et al. Phase II Study of Pegylated Arginine Deiminase for Nonresectable and Metastatic Hepatocellular Carcinoma. J Clin Oncol (2010) 28:2220-6. doi: 10.1200/jco.2009.26.7765

167. Ascierto PA, Scala S, Castello G, Daponte A, Simeone E, Ottaiano A, et al. Pegylated Arginine Deiminase Treatment of Patients With Metastatic Melanoma: Results From Phase I and II Studies. J Clin Oncol (2005) 23:7660-8. doi: 10.1200/jco.2005.02.0933

168. Harding JJ, Telli ML, Munster PN, Le MH, Molineaux C, Bennett MK, et al. Safety and Tolerability of Increasing Doses of CB-839, a First-in-Class, Orally Administered Small Molecule Inhibitor of Glutaminase, in Solid Tumors. J OF Clin Oncol (2015) 33:2512-2. doi: 10.1200/jco.2015.33.15_suppl.2512

169. Wu JM, Ho TW, Lai IR, Chen CN, Lin MT. Parenteral Glutamine Supplementation Improves Serum Albumin Values in Surgical Cancer Patients. Clin Nutr (2021) 40:645-50. doi: 10.1016/j.clnu.2020.06.015

170. Sands S, Ladas EJ, Kelly KM, Weiner M, Lin M, Ndao DH, et al. Glutamine for the Treatment of Vincristine-Induced Neuropathy in Children and Adolescents With Cancer. Support Care Cancer (2017) 25:701-8. doi: 10.1007/s00520-016-3441-6

171. Azman M, Mohd Yunus MR, Sulaiman S, Syed Omar SN. Enteral Glutamine Supplementation in Surgical Patients With Head and Neck Malignancy: A Randomized Controlled Trial. Head Neck (2015) 37:1799-807. doi: 10.1002/ hed.23839

172. Anderson PM, Lalla RV. Glutamine for Amelioration of Radiation and Chemotherapy Associated Mucositis During Cancer Therapy. Nutrients (2020) 12. doi: 10.3390/nu12061675

173. Abe T, Hosoi T, Kawai R, Uemura N, Higaki E, An B, et al. Perioperative Enteral Supplementation With Glutamine, Fiber, and Oligosaccharide Reduces Early Postoperative Surgical Stress Following Esophagectomy for Esophageal Cancer. Esophagus (2019) 16:63-70. doi: 10.1007/s10388-018-0630-Z

174. Long GV, Dummer R, Hamid O, Gajewski TF, Caglevic C, Dalle S, et al. Epacadostat Plus Pembrolizumab Versus Placebo Plus Pembrolizumab in Patients With Unresectable or Metastatic Melanoma (ECHO-301/ KEYNOTE-252): A Phase 3, Randomised, Double-Blind Study. Lancet Oncol (2019) 20:1083-97. doi: 10.1016/s1470-2045(19)30274-8

175. Ntambi JM. Regulation of Stearoyl-Coa Desaturase by Polyunsaturated Fatty Acids and Cholesterol. J Lipid Res (1999) 1549-58. doi: 10.1016/S0022-2275 (20)33401-5

176. Presler M, Wojtczyk-Miaskowska A, Schlichtholz B, Kaluzny A, Matuszewski M, Mika A, et al. Increased Expression of the Gene Encoding Stearoyl-Coa Desaturase 1 in Human Bladder Cancer. Mol Cell Biochem (2018) 40:217-24. doi: 10.1007/s11010-018-3306-Z

177. Lai KKY, Kweon SM, Chi F, Hwang E, Kabe Y, Higashiyama R, et al. Stearoyl-Coa Desaturase Promotes Liver Fibrosis and Tumor Development in Mice via a Wnt Positive-Signaling Loop by Stabilization of Low-Density Lipoprotein-Receptor-Related Proteins 5 and 6. Gastroenterology (2017) 447:1477-91. doi: 10.1053/j.gastro.2017.01.021

178. Gao Y, Li J, Xi H, Cui J, Zhang K, Zhang J, et al. Stearoyl-Coa-Desaturase-1 Regulates Gastric Cancer Stem-Like Properties and Promotes Tumour Metastasis via Hippo/YAP Pathway. Br J Cancer (2020) 152:1837-47. doi: 10.1038/s41416-020-0827-5

179. Aljohani A, Khan MI, Bonneville A, Guo C, Jeffery J, O’Neill L, et al. Hepatic Stearoyl Coa Desaturase 1 Deficiency Increases Glucose Uptake in Adipose Tissue Partially Through the PGC-1 $\alpha$-FGF21 Axis in Mice. J Biol Chem (2019) 122:19475-85. doi: 10.1074/jbc.RA119.009868

180. Wang J, Xu Y, Zhu L, Zou Y, Kong W, Dong B, et al. High Expression of Stearoyl-Coa Desaturase 1 Predicts Poor Prognosis in Patients With ClearCell Renal Cell Carcinoma. PloS One (2016) 294:e0166231. doi: 10.1371/ journal.pone.0166231 
181. Peck B, Schulze A. Lipid Desaturation - the Next Step in Targeting Lipogenesis in Cancer? FEBS J (2016) 11:2767-78. doi: 10.1111/febs.13681

182. Liu G, Feng S, Jia L, Wang C, Fu Y, Luo Y. Lung Fibroblasts Promote Metastatic Colonization Through Upregulation of Stearoyl-Coa Desaturase 1 in Tumor Cells. Oncogene (2018) 283:1519-33. doi: 10.1038/s41388-017-0062-6

183. Gao J, Zhang Z, Liu Y, Zhang Z, Wang M, Gong A, et al. Stearoyl-Coa Desaturase 1 Potentiates Hypoxic Plus Nutrient-Deprived Pancreatic Cancer Cell Ferroptosis Resistance. Oxid Med Cell Longev (2021) 37:6629804. doi: 10.1155/2021/6629804

184. Tutino V, Gigante I, Scavo MP, Refolo MG, Nunzio V, Milella RA, et al. Stearoyl-Coa Desaturase-1 Enzyme Inhibition by Grape Skin Extracts Affects Membrane Fluidity in Human Colon Cancer Cell Lines. Nutrients (2020) 2021:6629804. doi: 10.3390/nu12030693

185. Pisanu ME, Maugeri-Saccà M, Fattore L, Bruschini S, De Vitis C, Tabbì E, et al. Inhibition of Stearoyl-Coa Desaturase 1 Reverts BRAF and MEK InhibitionInduced Selection of Cancer Stem Cells in BRAF-Mutated Melanoma. J Exp Clin Cancer Res (2018) 12:318. doi: 10.1186/s13046-018-0989-7

186. Piao C, Cui X, Zhan B, Li J, Li Z, Li Z, et al. Inhibition of Stearoyl Coa Desaturase1 Activity Suppresses Tumour Progression and Improves Prognosis in Human Bladder Cancer. J Cell Mol Med (2019) 37:2064-76. doi: 10.1111/jcmm.14114

187. Ma XL, Sun YF, Wang BL, Shen MN, Zhou Y, Chen JW, et al. SphereForming Culture Enriches Liver Cancer Stem Cells and Reveals Stearoyl-Coa Desaturase 1 as a Potential Therapeutic Target. BMC Cancer (2019) 23:760. doi: 10.1186/s12885-019-5963-z

188. Ma MKF, Lau EYT, Leung DHW, Lo J, Ho NPY, Cheng LKW, et al. StearoylCoa Desaturase Regulates Sorafenib Resistance via Modulation of ER Stress-
Induced Differentiation. J Hepatol (2017) 19:979-90. doi: 10.1016/ j.jhep.2017.06.015

189. Pisanu ME, Noto A, De Vitis C, Morrone S, Scognamiglio G, Botti G, et al. Blockade of Stearoyl-Coa-Desaturase 1 Activity Reverts Resistance to Cisplatin in Lung Cancer Stem Cells. Cancer Lett (2017) 67:93-104. doi: 10.1016/j.canlet.2017.07.027

190. Potze L, di Franco S, Kessler JH, Stassi G, Medema JP. Betulinic Acid Kills Colon Cancer Stem Cells. Curr Stem Cell Res Ther (2016) 11:427-33. doi: $10.2174 / 1574888 \times 11666151203223512$

Conflict of Interest: The authors declare that the research was conducted in the absence of any commercial or financial relationships that could be construed as a potential conflict of interest.

Publisher's Note: All claims expressed in this article are solely those of the authors and do not necessarily represent those of their affiliated organizations, or those of the publisher, the editors and the reviewers. Any product that may be evaluated in this article, or claim that may be made by its manufacturer, is not guaranteed or endorsed by the publisher.

Copyright $\odot 2021 \mathrm{Bao}, \mathrm{Xu}, \mathrm{Lu}$, Huang, Pan and Ge. This is an open-access article distributed under the terms of the Creative Commons Attribution License (CC BY). The use, distribution or reproduction in other forums is permitted, provided the original author(s) and the copyright owner(s) are credited and that the original publication in this journal is cited, in accordance with accepted academic practice. No use, distribution or reproduction is permitted which does not comply with these terms. 